\title{
Local Conditions Structure Unique Archaeal Communities in the Anoxic Sediments of Meromictic Lake Kivu
}

\author{
Susma Bhattarai - Kelly Ann Ross • Martin Schmid • \\ Flavio S. Anselmetti • Helmut Bürgmann
}

Received: 31 October 2011 / Accepted: 26 February 2012 /Published online: 20 March 2012

(C) Springer Science+Business Media, LLC 2012

\begin{abstract}
Meromictic Lake Kivu is renowned for its enormous quantity of methane dissolved in the hypolimnion. The methane is primarily of biological origin, and its concentration has been increasing in the past half-century. Insight into the origin of methane production in Lake Kivu has become relevant with the recent commercial extraction of methane from the hypolimnion. This study provides the first culture-independent approach to identifying the archaeal communities present in Lake Kivu sediments at the sediment-water interface. Terminal restriction fragment length polymorphism analysis suggests considerable heterogeneity in the archaeal community composition at varying sample locations. This diversity reflects changes in the geochemical conditions in the sediment and the overlying water, which are an effect of local groundwater inflows. A more in-depth look at the archaeal community composition by clone library analysis revealed diverse phylogenies of Euryarchaeota and Crenarachaeota. Many of the sequences in the clone libraries belonged to globally distributed archaeal clades such as the rice cluster V and Lake Dagow sediment environmental clusters. Several of the determined clades were previously thought to be rare among freshwater sediment Archaea (e.g., sequences related to the SAGMEG1 clade). Surprisingly, there was no observed relation of clones to known hydrogentrophic methanogens and less
\end{abstract}

Electronic supplementary material The online version of this article (doi:10.1007/s00248-012-0034-x) contains supplementary material, which is available to authorized users.

S. Bhattarai · K. A. Ross · M. Schmid · F. S. Anselmetti ·

H. Bürgmann $(\triangle)$

Department of Surface Waters-Research and Management, Eawag, Swiss Federal Institute for Aquatic Science and Technology,

Seestrasse 79,

6047 Kastanienbaum, Switzerland

e-mail: helmut.buergmann@eawag.ch than $2 \%$ of clones were related to acetoclastic methanogens. The local variability, diversity, and novelty of the archaeal community structure in Lake Kivu should be considered when making assumptions on the biogeochemical functioning of its sediments.

\section{Introduction}

Meromictic Lake Kivu in East Central Africa is well known as a huge reservoir of dissolved methane $\left(\mathrm{CH}_{4}\right)$ and carbon dioxide $\left(\mathrm{CO}_{2}\right)$. The enormous quantities of gases trapped in the stratified deep water make Lake Kivu the largest of the "exploding lakes", which further include the two Cameroonian crater lakes Lake Nyos [1] and Lake Monoun [2]. Lake Kivu is an African Rift lake surrounded by the active Virunga volcanoes. It is fed by precipitation and a large number of small streams but has no major river inflow. In addition, several sources of groundwater enter in the lake at various depths, which explains the strong gradients observed in the vertical profiles of salinity, temperature, and dissolved gasses [3]. Hydrothermal groundwater sources supply heat and salt to the bottom of the lake $[4,5]$ while colder, less saline groundwater enters the lake at shallower depths. The conjunction of the groundwater sources result in a highly stable stratification of the water column. However, the details of how the groundwater inflows affect the unique geochemical and physical properties of Lake Kivu is not yet well understood and is currently being investigated.

The dissolved $\mathrm{CH}_{4}$ in Lake Kivu amounts to a volume of approximately $60 \mathrm{~km}^{3}$ (at $0^{\circ} \mathrm{C}$ and $1 \mathrm{~atm}$ ) [3]. $\mathrm{CH}_{4}$ is drawing global attention as a significant greenhouse gas, which accounts for $14 \%$ of the anthropogenic greenhouse gas emissions and $18 \%$ of the increase in radiative forcing effect [6]. Lakes and reservoirs have been identified as 
major contributors to the global $\mathrm{CH}_{4}$ budget. A recent estimate for $\mathrm{CH}_{4}$ emission from freshwater sources of $103 \mathrm{Tg}$ of $\mathrm{CH}_{4}$ year ${ }^{-1}$ is higher than for oceanic $\mathrm{CH}_{4}$ [7-9]. Due to the risk of catastrophic outgassing, the accumulated $\mathrm{CH}_{4}$ in Lake Kivu has to be considered as a threat to the population living in and around the catchment. However, the $\mathrm{CH}_{4}$ also promises to be a valuable energy resource for both riparian countries. Smallscale $\mathrm{CH}_{4}$ extraction plants are currently in operation in Lake Kivu and implementation of large-scale $\mathrm{CH}_{4}$ exploitation is under way [10].

The $\mathrm{CO}_{2}$ accumulated in Lake Kivu is of geogenic origin, as is evident from the ${ }^{14} \mathrm{C}$ signature of $\mathrm{CO}_{2}$ [11]. In contrast, the $\mathrm{CH}_{4}$ is thought to be primarily the result of biological methanogenesis [11-13], although an additional influx of geogenic $\mathrm{CH}_{4}$ has not been ruled out. Significant information on geological, physical, and chemical processes in Lake Kivu has accumulated from intensive research performed over the past few decades [14-17]. Recently, evidence for a contemporary increase in $\mathrm{CH}_{4}$ concentrations has been presented $[3,11]$ and linked to changes in the lake's food web, hydrological conditions, and nutrient input [11, 15]. This has considerable implications both for the assessment of the risks of violent outgassing, as well as for the planned $\mathrm{CH}_{4}$ exploitation for energy production. The currently observed increase in $\mathrm{CH}_{4}$ clearly indicates the importance of understanding the processes of methanogenesis in Lake Kivu.

Methanogenesis has been found to be exclusively performed by Archaea. However, Archaea are now known to be involved in various other metabolic pathways, including sulfate reduction [18] and ammonia-oxidation [19]. Lake sediments are generally anoxic below a zone of steep gradients of organic substrates and electron acceptors frequently extending not more than a few millimeters below the sediment-water interface. Methanogenesis is the most important terminal electron acceptor process in the mineralization of organic compounds when oxygen, nitrate, metal oxides, and sulfate have been depleted as electron acceptors [20, 21]. Below $90 \mathrm{~m}$ depth, the water column of Lake Kivu is devoid of these external electron acceptors [11]. Therefore, the microbial community in its sediment is expected to be dominated by a consortium of fermentative microorganisms, methanogenic Archaea, and possibly chemolithotrophic acetogens. For sediments below $90 \mathrm{~m}$ depth, we would therefore expect limited spatial variability in the microbial community composition, as the water column of the lake is also horizontally homogenous [11]. However, in the areas where sediments are in direct contact with groundwater inflows, local conditions and the resulting microbial communities are expected to diverge from this homogeneity. Additionally, there are pronounced gradients in chemical and physical properties in the water column, e.g., temperature, salinity, alkalinity, and $\mathrm{CH}_{4}$ concentrations, which could potentially affect microbial populations in sediments at different depths.
With the development of modern molecular methods, members of the domain Archaea have been shown to be an ubiquitous and diverse component of the microbial communities in marine sediment and water [22-25]. In comparison, much less is known about the community structure and diversity of Archaea in freshwater sediments, especially in deep lakes. Two recent studies have characterized the microbial population of Lake Kivu waters using modern cultureindependent molecular methods $[11,26]$. Those studies were focused specifically on $\mathrm{CH}_{4}$ oxidizers and methanogens in the entire water column [11] and on non-methanogenic Archaea down to $100 \mathrm{~m}$ water depth [26], respectively. To date, the diversity and community structure of Archaea in the lake sediment remains unexplored, with exception of a culturebased study that succeeded in cultivating Methanosarcina-like organisms [12, 27].

In the present study, we describe the archaeal community composition in Lake Kivu sediment (KS) and investigate their spatial variability in relation to the influence of the local geochemistry and sedimentology of the lake. We also expected to identify rRNA gene sequences of methanogenic Archaea to provide the first culture-independent identification of the methanogens in the lake sediment. We analyzed 13 surface sediment samples from different water depths and various locations in the northern basin of Lake Kivu and obtained extensive information on the community structure and diversity of Archaea using terminal restriction fragment length polymorphism (T-RFLP) analysis and sequencing of clone libraries.

\section{Materials and Methods}

\section{Sampling Sites and Sample Collection}

Lake Kivu has a maximum depth of $485 \mathrm{~m}$. The study was carried out in the northern basin of the lake (Fig. 1). The lake is located in the East African Rift near the active volcanoes Niyamulagira and Nyiragongo. About $1.3 \mathrm{~km}^{3}$ year $^{-1}$ of water enter the lake as sub-aquatic inflows below its mixolimnion, which explains the strong gradients observed in vertical profiles of temperature, salinity and dissolved gasses [3]. The groundwater inflows are crucial for the establishment of a stable stratification. Therefore, the sampling sites were chosen to encompass areas locally influenced by known groundwater inflows, as well as sites representing general basin conditions at a range of depths above and below the main chemocline.

We analyzed 13 surface sediment samples from cores collected at different water depths (Fig. 1). KS cores KS5, KS20, and KS21 were collected in the deepest part of the basin. Core KS4 was taken further to the north, from a location on a ridge above the main chemocline. Cores 


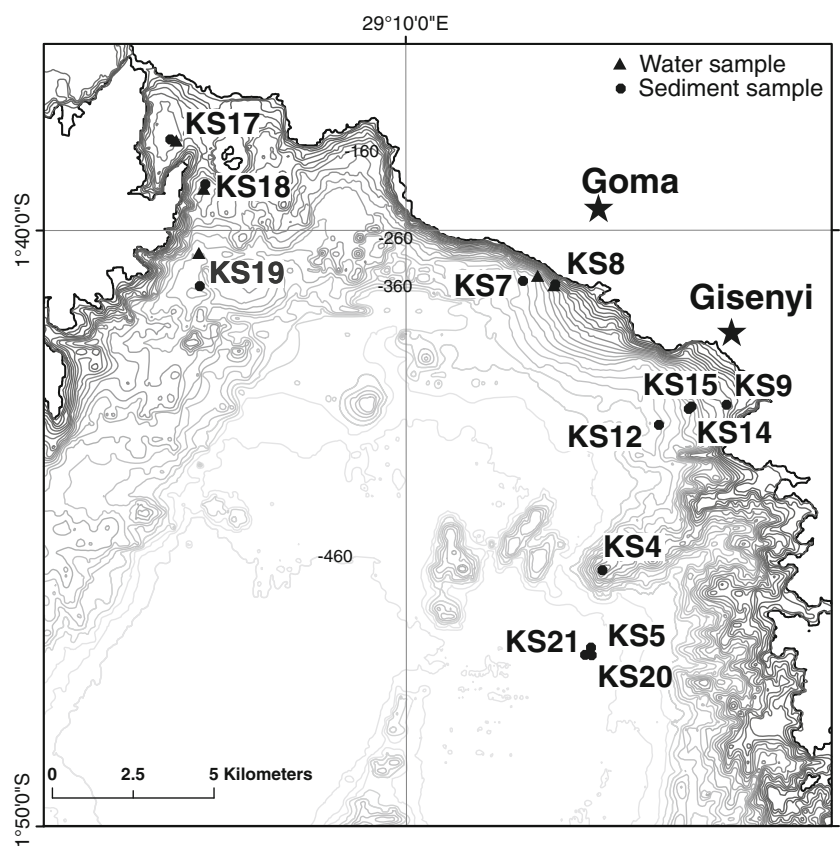

Figure 1 Bathymetric map of the northern basin of Lake Kivu showing the locations from where samples were collected. Adapted from Ref. item [69]

KS9, KS12, KS14, and KS15 were obtained from various water depths along a transect offshore of the city of Gisenyi. KS7 and KS8 were collected in the vicinity of relatively cool and fresh groundwater inflows detected near Goma. KS17, KS18, and KS19 were collected from the northwestern area, which is influenced by hydrothermal inflows. Among these, KS17 and KS18 were located directly beneath warm, saline water filling a local depression and a channel, respectively.

Sediment cores were retrieved with a gravity short-corer. Due to the high concentration of gas in the lake below $200 \mathrm{~m}$ depth, sediment cores from these water depths degassed strongly for several minutes, consequently disturbing the original sediment structure. Core KS17 from the hydrothermal area (145 $\mathrm{m}$ water depth) also degassed. The other cores taken from less than $200 \mathrm{~m}$ water depth (KS4, KS8, and KS9) remained undisturbed. Disturbed cores were left to settle overnight. Sediment (10-20 g) samples were obtained using sterile technique from the top (upper $5-\mathrm{cm}$ section) of the sediment core. The samples were collected in sterilized Falcon tubes and preserved immediately with $\sim 20 \mathrm{~mL}$ of $70 \%$ ethanol.

Water samples for chemical analysis were collected close to the coring locations KS17 and KS18 (hydrothermal area) and KS8 and KS7 (cold groundwater area), and near coring location KS19 with a 5-liter Niskin bottle as described by Pasche et al. [16]. For depths below $200 \mathrm{~m}$, the open valve at the top of the Niskin bottle was capped with a balloon to prevent sample loss from vigorous outgassing during ascent. Subsamples of each water sample was filtered through $0.45-\mu \mathrm{m}$ pore-size polycarbonate filters (Whatman, Bottmingen, Switzerland) using a sterile $50-\mathrm{mL}$ syringe at the time of sampling. A subsample $(10 \mathrm{~mL})$ of the filtered water was acidified with $200 \mu \mathrm{l}$ of supra-pure concentrated $\mathrm{HNO}_{3}$ for inductively coupled plasma-mass spectrometry (ICP-MS) analysis. An additional subsample of filtered water was also used for alkalinity titration.

\section{Sediment Characterization}

Color and texture of the surface sediment were noted on the basis of visual inspection during sampling. Smear slides were prepared and observed under a light microscope under crossand plane-polarized light to identify minerals and diatoms. Images obtained at $\times 40$ magnification were analyzed and compared among the different sediment samples. The abundance of diatoms, carbonates, and clastic silicates (identified by shape, color, and appearance in polarized light) were estimated from the images.

Total carbon (TC), total nitrogen, and total sulfur (TS) were measured by combustion at $1,000^{\circ} \mathrm{C}$ in a CNS elemental analyzer (EuroEA 3000, Eurovector, Milano, Italy) as described previously [15]. Total inorganic carbon (TIC) was measured as $\mathrm{CO}_{2}$ by coulometry [15]. Total organic carbon (TOC) was calculated as the difference of TC and TIC. In order to derive estimates of sediment composition, organic matter $(\mathrm{OM})$ was estimated from TC by multiplication with 2 [28] and carbonate was estimated from TIC by multiplying with 8.3 (assuming that all inorganic carbon is bound as calcium carbonate; molecular weight ratio $\left.\mathrm{C} / \mathrm{CaCO}_{3}=8.3\right)$.

\section{Chemical Analysis of Water}

Vertical profiles of water temperature, conductivity, and $\mathrm{pH}$ were recorded in situ with a Seabird SBE-19 conductivity, temperature, and depth (CTD) probe (Sea-Bird Electronics, Inc., Bellevue, WA). The analysis was performed following the previously described method [16]. Standard methods [29] were applied for colorimetric analyses of $\mathrm{SO}_{4}{ }^{2-}$ and $\mathrm{S}(-\mathrm{II})$ with a portable photometer (Merck Nova 60, VWR). Dissolved iron was measured with ICP-MS and ICP-OES. Alkalinity was titrated using a 716 DMS Titrino (Metrohm, Herisau, Schweiz) and $0.1 \mathrm{~mol} \mathrm{~L}^{-1} \mathrm{HCl}$.

\section{Molecular Analysis}

\section{DNA Extraction and PCR Amplification}

Ethanol was separated from preserved sediment by centrifugation $(10 \mathrm{~min}$ at $8,000 \times \mathrm{g})$. DNA was extracted from the sediment sample by bead beating for $45 \mathrm{~s}$ at speed $5.5 \mathrm{~ms}^{-1}$, 
a mechanical method of cell lysis. The bead mix contained $0.5 \mathrm{~g}$ of sediments, $0.1 \mathrm{~g}$ of $106 \mu \mathrm{m}$ beads, and $0.1 \mathrm{~g}$ of 150 $212 \mu \mathrm{m}$ beads (both Sigma, Buchs, Switzerland) in $1.5 \mathrm{~mL}$ of GOS extraction buffer [30]. The DNA were separated with phenol/chloroform and precipitated with ethanol. Then, the DNA was resuspended in sterile TE buffer and stored at $-20^{\circ} \mathrm{C}$.

Polymerase chain reaction (PCR) amplification of archaeal 16S rRNA genes was based on an optimization of the protocol described earlier [31] using primers Ar109f 5'AC(GT)GCTCAGTAACACGT-3' [32] and Ar915r 5'GTGCTCCCCCGCCAATTCCT-3' [33] specific for the domain Archaea. The reaction mixture $(50 \mu \mathrm{L})$ contained $1 \mu \mathrm{L}$ of template DNA ( 10 ng), $0.2 \mu \mathrm{M}$ of each primer, $2 \mathrm{mM}$ magnesium chloride $\left(\mathrm{MgCl}_{2}\right), 0.5 \mathrm{mM}$ of each deoxynucleoside triphosphate, $1 \mathrm{mg} \mathrm{mL}^{-1}$ of bovine serum albumin (BSA), $\times 1$ PCR buffer $\left(\mathrm{MgCl}_{2}\right.$ free), $1.25 \mathrm{U}$ of Taq DNA polymerase (all Promega, Mannheim, Germany) and nuclease free water (QIAGEN, Hilden, Germany). PCR amplification was performed on a Touchgene Gradient Thermal Cycler (Techne, Cambridge, UK) with the following temperature program: initial denaturation at $95^{\circ} \mathrm{C}$ for $2 \mathrm{~min}$, followed by 30 cycles of denaturation at $94^{\circ} \mathrm{C}$ for $30 \mathrm{~s}$, annealing at $52^{\circ} \mathrm{C}$ for $45 \mathrm{~s}$, and elongation at $72^{\circ} \mathrm{C}$ for $30 \mathrm{~s}$. The final elongation step was extended to $7 \mathrm{~min}$. Five microliters of the amplicons were visualized by standard agarose gel electrophoresis ( $2 \%$ agarose gel, $1 \mu \mathrm{L}$ of gel red for fluorescence, and a running voltage of $80 \mathrm{~V}$ for $45 \mathrm{~min}$ ) and documented using a GelDoc UV transilluminator (Fusion FX7, Witec, Switzerland). Weak PCR products (samples KS14 and KS18) were amplified again from the sample and equal quantities of three replicate PCR products were pooled using the Wizard ${ }^{\circledR}$ SV Gel and PCR CleanUp system (Promega). All PCR products were quantified on a NanoDrop 1000 Spectrophotometer (Thermo Fisher Scientific Inc., NanoDrop products, Wilmington, USA) prior to further processing.

\section{T-RFLP Analysis}

For T-RFLP analysis of archaeal communities, the same PCR reaction as described above was carried out except that a FAM (5'6-carboxy-fluorescein)-labeled Ar109f forward primer was used. Aliquots of the cleaned archaeal PCR amplicons (50 ng) were digested with TaqI restriction endonuclease (Promega) for $3 \mathrm{~h}$ at $65^{\circ} \mathrm{C}$ as described previously [31]. The digestion mixture contained $5 \mu \mathrm{L}$ of DNA amplicons, $2 \mu \mathrm{L} 10 \mathrm{x}$ restriction buffer, $0.2 \mu \mathrm{L}$ of BSA $(10 \mu \mathrm{g} / \mu \mathrm{L})$, and $0.5 \mu \mathrm{L} \mathrm{TaqI}(10 \mathrm{U} / \mu \mathrm{L})$ along with nuclease free water achieving a total volume of $20 \mu \mathrm{L}$. The restriction digests were screened by acrylamide gel electrophoresis prior to T-
RFLP analysis. Electrophoresis of digested amplicons was performed following a previously described T-RFLP protocol with slight modifications [33]. Briefly, $2 \mu \mathrm{L}$ of digested amplicons were mixed with $8 \mu \mathrm{L}$ of Hi-Di formamide (Applied Biosystems, Weiterstadt, Germany) and $0.5 \mu \mathrm{L}$ of GeneScan $^{\mathrm{TM}} 1200$ LIZ $^{\circledR}$ Size Standard (Applied Biosystems), denatured $\left(3 \mathrm{~min}\right.$ at $\left.95^{\circ} \mathrm{C}\right)$, cooled on ice, and size-separated on an Applied Biosystems 3130xl genetic analyzer. Electrophoresis was performed with POP-7 polymer in 50-cm-by-50$\mu \mathrm{m}$ capillaries under the following conditions: $25 \mathrm{~s}$ injection time, $18 \mathrm{kV}$ injection voltage, $15 \mathrm{kV}$ run voltage, and $60^{\circ} \mathrm{C}$ run temperature.

The peak area and peak size tables were obtained from the Gene Mapper ${ }^{\circledR}$ Software version 4.0 (Applied Biosystems). The tables were converted to sample area and fragment size tables, then converted to binned operational taxonomic unit (OTU) tables by using a custom R binning script [34]. A window size of $2 \mathrm{bp}$ and shift value of $0.1 \mathrm{bp}$ was selected for the binning by using the window shifting algorithm of the script. On the basis of control samples (T-RFLP profiles from Methanosarcina barkeri (DSM800)) only peaks ranging between 100 and 1,000 bp size and with a relative fluorescence intensity value of $\geq 0.09 \%$ of the run total were considered for analysis.

\section{Cloning and Sequencing}

Based on similarity analysis of T-RFLP profiles (see "Results"), clone libraries were constructed using DNA extracts from six locations (KS7, KS8, KS9, KS17, KS18, and KS20) in the northern basin of Lake Kivu.

The gel bands of expected size ( $815 \mathrm{bp}$ ) were excised under UV light and the PCR amplicons were cleaned using Wizard ${ }^{\circledR}$ SV Gel and PCR Clean-Up system following the manufacturer's protocol (Promega). Clean PCR products were cloned using the GEM $^{\circledR}$-T Easy Vector System cloning kit (Promega). Per clone library, two plates using 20 and $100 \mu \mathrm{l}$ of transformed cell suspension were prepared for bluewhite screening according to the manufacturer's protocol, yielding $>60$ white colonies. Approximately, 30 clones per clone library were randomly selected and positive transformants were confirmed by screening for correct insert size using the PCR as described above (omitting BSA) followed by agarose gel electrophoresis. Sequencing was performed by Microsynth AG (Balgach, Switzerland).

Sequences were subjected to in-silico T-RFLP analysis using TRiFLe [35]. For comparison, measured T-RFLP sizes were corrected using the correction term published by Kaplan and Kitts [36]. OTUs with predicted T-RFLP fragment sizes that were within $\pm 2 \mathrm{bp}$ of the in silico determined fragment size were considered to be matching. 
Statistical Analysis

Statistical tests, data calculation, and graphics were produced with R software version 2.12.1 [37]. R packages used for the analysis were vegan [38], and BiodiversityR [39].

The analysis of ecological distance by unconstrained ordination was performed using principal component analysis of the relative T-RFLP peak area matrix as described by Boccard et al. [40]. The relative peak area data were Hellinger transformed prior to analysis [41].

\section{Phylogenetic Analysis}

Sequence reads were manually screened and vector and primers sequences trimmed. We checked for chimeric sequences with the Bellerophon server application at the greengenes.lbl. gov site (http://greengenes.lbl.gov/cgi-bin/nph-bel3 interface. cgi) [42], and five chimeric sequences were excluded. The gene sequences were classified using the Classifier tool on the Ribosomal Database Project (RDP) release 10 website (http://rdp.cme.msu.edu/) [43], confirming the archaeal identity of the 16S rRNA gene insert in all the clones analyzed. The final dataset included 167 sequences.

Two independent phylogenetic assessments were performed. In the first approach, reference sequences of cultured Archaea were selected from the best matches available in the RDP database through the SeqMatch tool and imported to MEGA version 5 [44]. Some additional reference sequences of important clades not covered by search results were added manually in the RDP taxonomy browser. The environmental reference sequences were obtained based on the available best matches from BLAST searches of GenBank [45] (http://blast. ncbi.nlm.nih.gov/) and RDP SeqMatch searches and keyword queries using the Entrez database query tool (http://www.ncbi. nlm.nih.gov/nuccore). Additional reference sequences affiliated with the environmental archaeal clusters Lake Dagow sediment (LDS) and rice cluster V (RC-V) as published by [46] were obtained from the Electronic Supplementary Material (ESM) available from the publishers website. All sequences were aligned to the RDP global archaeal alignment using the RDP aligner. A phylogenetic tree was constructed de-novo using the unweighted pair group mean (UPGMA) hierarchical clustering method [47]. The evolutionary distances of the phylogenetic tree were computed by the Kimura two-parameter method [48] as implemented in MEGA 5 [44], using pair wise gap elimination and 500 bootstrap re-samplings for tree testing. Based on this tree, Lake Kivu sequences were grouped, and phylogenetic clades were labeled in accordance with the known phylogeny of reference sequences and based on the results of the ARB tree (see below).
In a second approach sequences were first aligned to the Greengenes rRNA database using NAST (http://greengenes.lbl. gov/cgi-bin/nph-NAST_align.cgi). The aligned sequences were then imported into ARB [49] and inserted into the reference tree supplied with the Greengenes 2011 16S rRNA ARB database (Greengenes_16S_2011_1.arb, 03-May-2011) using the ARB parsimony method. The phylogenetic placement of the sequences relative to the Greengenes/Hugenholtz taxonomy [50] was noted and also used in the annotation of the de novo tree described above.

For comparison with published data, a literature search for studies on archaeal communities in lake sediments was conducted. Studies reporting archaeal clone libraries from lake sediments consisting of more than 20 clones were considered for analysis. Two libraries deposited in GenBank (Lake Honghu and Lake Pavin) but not yet published in print were also included. Sequences were retrieved from GenBank using the BatchEntrez tool with the published accession numbers. Each set of sequences was aligned to the RDP database together with the Kivu clones and reference sequences (the reference dataset). A phylogenetic tree was constructed for each aligned dataset as described above. Based on these trees, the sequences were assigned to the phylogenetic groups that had been established from the phylogenetic analysis of the original reference dataset. The number of sequences assigned to each group were counted. In cases where only representative sequences were submitted to GenBank, we obtained the original dataset [51] or counts were adjusted based on the information given in the publication [52].

Rarefaction curves and library coverage (Good's coverage, $C=1-\frac{n_{1}}{N}$, with $n_{1}=$ number of OTUs sampled once, and $N$ total number of individuals) were calculated using MOTHUR software [53]. For these calculations, an operational OTU definition using a $10 \%$ similarity cutoff was used.

\section{Nucleotide sequence accession numbers}

The 16S rRNA gene sequences obtained from this study have been deposited in the GenBank database under accession numbers JN853604-JN853770.

\section{Results}

Sediment Characteristics

The surface sediment samples were categorized in four lithological groups (S1-S4) on the basis of color, grain size, 
and mineralogical composition (Table 1). The sediments from the transect offshore of Gisenyi (group S1) were distinguished by the dark color, larger proportions of siliciclastics $(\sim 70 \%)$, and low TOC content (3-4\%). All S1 sediments contained circular diatoms inferred to be Cyclotella sp. while other samples mostly contained diverse, but dominantly thin, elongated diatoms inferred to be Nitzschia sp. [15].

Group S2 included the sediment samples originating from the deep parts of the main Kivu basin (KS5, KS20, and KS21). S2 sediments appeared as a shiny brown-colored mud. S2 sediments appeared quite uniform in their chemical and mineralogical properties with abundant diatoms, high contents of TOC (7-8 \%), and moderate amounts of carbonates (14-15\%) (Table 1).

Sediments of the S3 group originated from the vicinity of the cold groundwater inflows (KS7 and KS8) and from the basin ridge site (KS4). They were characterized by dark greenish color with white patches, the latter likely consisting of remains of carbonate layers disturbed during sampling. $\mathrm{S} 3$ sediments were quite variable in their mineralogical composition (5-48\% carbonate and 6-9 \% TOC), but contained a similar assemblage of diatoms as $\mathrm{S} 2$. The samples from the cold groundwater area were characterized by a high TS content ( 7\%).

Samples in group S4 originated from the hydrothermal area to the northwest. Similar to S3 samples, they appeared greenish in color with a fluffy and flocculent texture. S4 samples had the highest TS content compared with other sediment groups. Sample KS18 was unique, as it contained only $\sim 6 \%$ carbonates and had an exceptionally high TS content $(\sim 11 \%)$. These sediments mostly contained diverse diatoms similar to group S2; however, KS19 was distinguished by the presence of Cyclotella sp.

\section{Water Chemistry}

We compared water chemistry data from this sampling campaign with previously published data on the average chemistry of Lake Kivu's water column [16] to demonstrate the local influence of the groundwater inflows. The water mass above coring locations KS17 and KS18 was warmer and more saline than that at the same depth in the main basin (Fig. 2a). Alkalinity and $\mathrm{pH}$ also deviated from the main basin with an exceptionally high alkalinity value of $82 \mathrm{mmol} \mathrm{L}^{-1}$ for the KS17 sample, and a substantially lower pH (Fig. 2b). Additionally, about $280 \mu \mathrm{mol} \mathrm{L}^{-1}$ of dissolved iron was detected in the water sample above KS17 whereas dissolved iron was $<1 \mu \mathrm{M}$ in most other samples and in the main basin.

The cold spring influence can be seen in the reduced temperature in the water sampled above KS8 and reduced alkalinity in the water sampled above KS8 and KS7 (Fig. 2).
We further observed an increased dissolved iron concentration $(10 \mu \mathrm{M})$ and a high total sulfur content was measured above $\mathrm{KS} 7$, in excess of the $\mathrm{SO}_{4}{ }^{2-}+\mathrm{S}(\mathrm{II})$ sulfur concentrations at this depth in the main basin.

\section{Archaeal Community Structure}

A total of 50 distinct OTUs were detected in the archaeal TRFLP profiles of Lake Kivu across the 13 analyzed sediment samples. The average number of OTUs observed in an individual T-RFLP profile was 12 . The number of OTUs fluctuated considerably among the sediment samples from a minimum of 3 OTUs (sample KS14) to 20 OTUs (sample KS20) (Fig. 3a; also see electropherogramms in Fig. S1 in the ESM).

An ordination plot was derived from principal component analysis (PCA) of the OTU abundance dataset, and displayed differences and similarities in the archaeal population structure based on T-RFLP data (Fig. 3b). Most samples with an origin from below the chemocline are located near the bottom of the graph (negative values on the principal component axis 2 (PC2)). Sediment group S2 samples aggregated in the bottom right quadrant of the PCA plot. These samples, as well as KS14 (S1) and KS17 (S4), were characterized by a high abundance of OTU50. KS7 (S3), which like the $\mathrm{S} 2$ samples originates from below the main chemocline, is placed in between the other $\mathrm{S} 3$ samples from above the chemocline (KS8 and KS4) and the S2 samples. S1 samples (KS9, KS12, and KS15) from the transect offshore Gisenyi were observed to have an archaeal community composition distinctly different from other sediment groups. KS12 is the only sample in this group originating from below the chemocline, but it did not display a distinct archaeal community, although it has the lowest PC2 value. KS14 was distant from the rest of the group along axis1. S4 samples did not cluster together and KS18 and KS17 were distinct from all other sediments. KS18 had a unique OTU composition with OTU17, OTU18, and OTU31 being dominant. OTU17 was common in both KS18 and KS14 samples, while OTU18, and OTU31 were abundant in K18 but rare in all other sediment samples. KS19, which originated below the chemocline, clustered near the shallow S3 samples KS4 and KS8.

\section{Phylogenetic Diversity}

Phylogenetic analysis of archaeal 16S rRNA gene sequences revealed the presence of phylogenetically diverse Archaea in KS (Fig. 4a). The vast majority of the sequences were not affiliated with any cultured reference strains. Based on this tree, we identified nine major phylogenetic clusters among our clones, which were labeled KS group (KSGR) 1 through 9 in Fig. 4a. Out of these, KSGR-1 (clone frequency $25 \%$ ), 


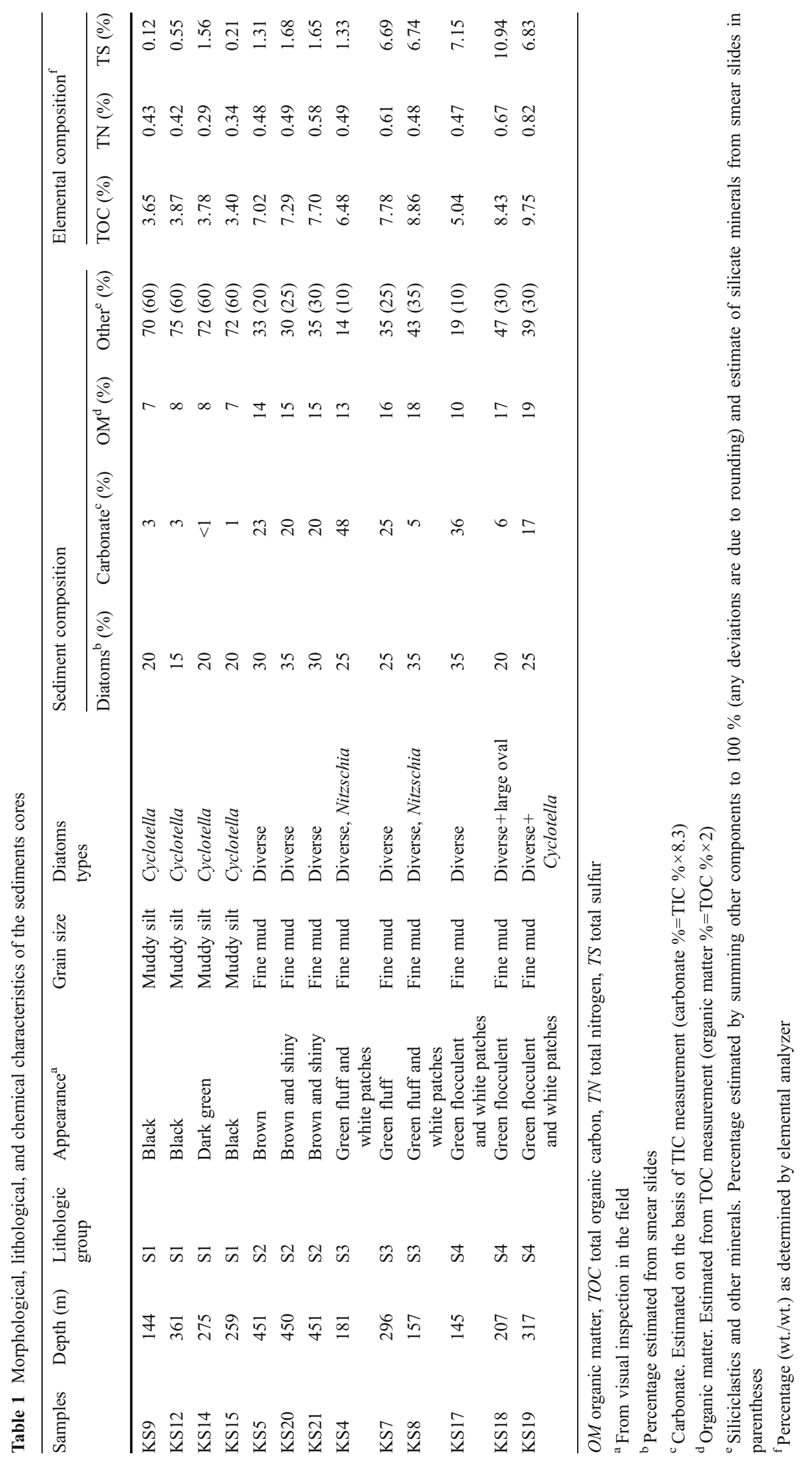


a

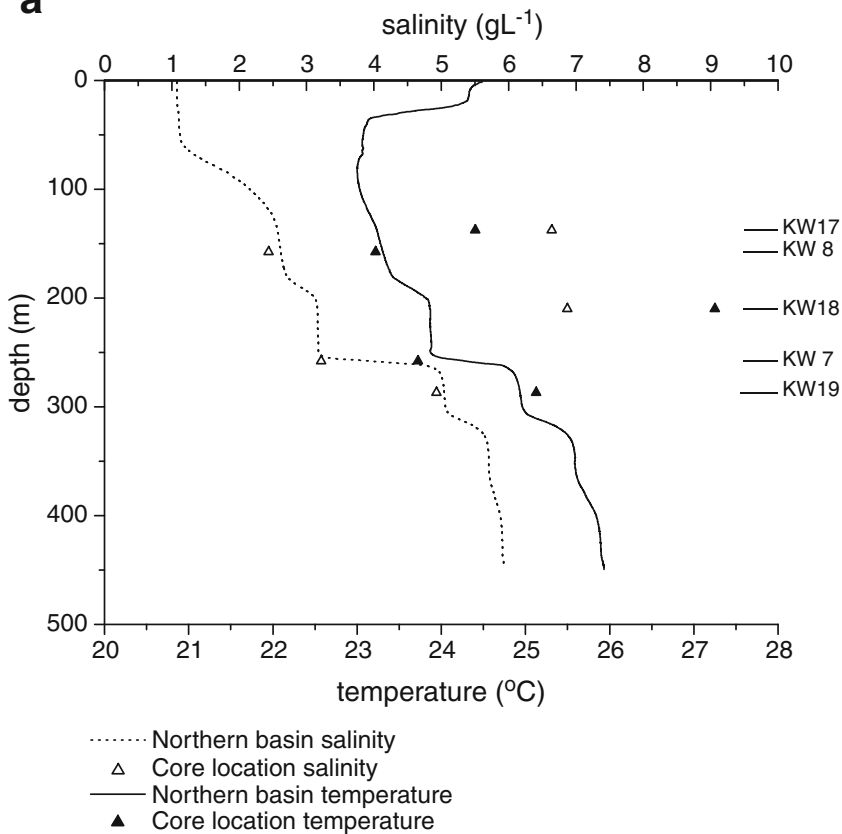

Figure 2 Vertical profiles of a salinity and temperature and $\mathbf{b}$ alkalinity $\left(\mathrm{HCO}_{3}{ }^{-}\right)$and $\mathrm{pH}$. Lines represent the average of four measurements in the main basin as determined previously [16]. Symbols represent our measurements from the northern basin determined from CTD casts near the

KSGR-6 (18 \%), KSGR-8 (12 \%), and KSGR-9 (23 \%) were overall most frequently represented in our six clone libraries (Table 2). These groups, which together contained almost $80 \%$ of the sequences obtained, were associated with diverse environmental sequences affiliated with the phyla Euryarchaeota and Crenarchaeota.

\section{Crenarchaeota}

The KSGR-1 cluster was affiliated with the Crenarchaeota and contained three discernible subclusters (Figs. 4a and 5d). KSGR-1c formed a separate branch with uncultured crenarchaeota from a geothermal spring [54]. In the ARB analysis (Fig. 4b) KSGR-1a and 1c clustered together with several subclusters of the $\mathrm{C} 2$ cluster of environmental Crenarchaeota. Many of the Kivu sequences in this group were most closely affiliated with uncultured Crenarchaeota sequences derived from phreatic limestone sinkholes in Mexico [55]. KSGR-1b included two sequences related to cluster Sd-NA and sequence KS9-12 that was up to $96 \%$ similar to Candidatus Nitrososphaera sp., which are members of the Thaumarchaeota [19].

\section{Euryarchaeota}

KSGR-6 was associated with uncultured groups of the Thermoplasmatales. The most similar sequences came from various lake sediments, specifically from Lake Pavin (France) and b

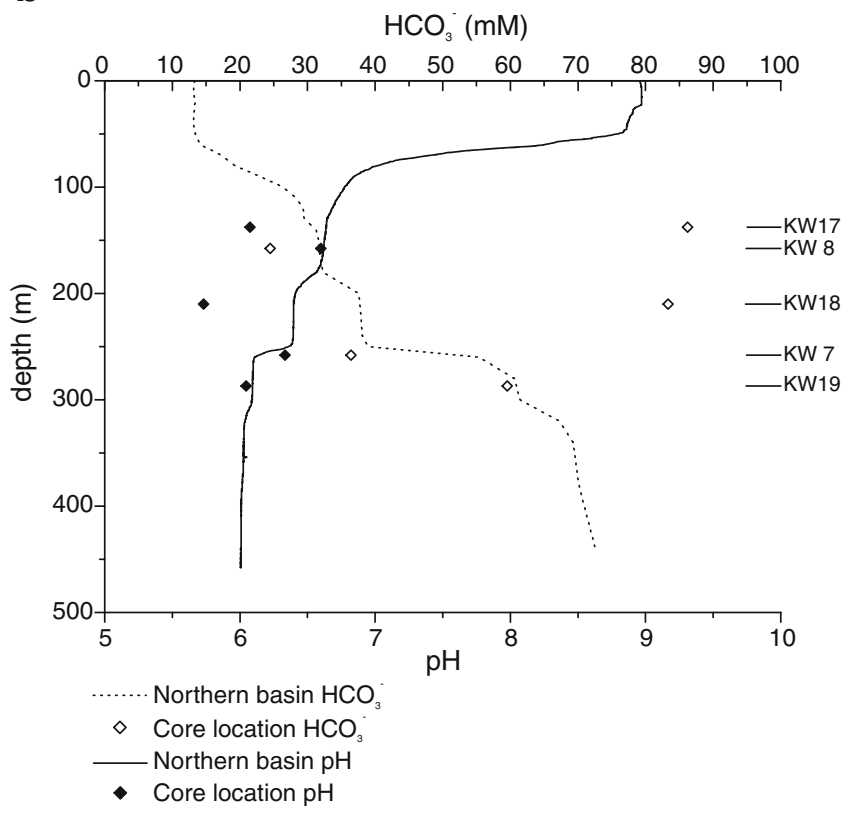

coring sites (a) and water samples taken from the vicinity of the sediment cores (b) in January 2010. The $\mathrm{HCO}_{3}{ }^{-}$value at 200-m depth was estimated from conductivity, which is linearly correlated with alkalinity in the main basin

Lake Honghu (China) (Fig. 5a). Three subclusters could be distinguished within this group: in the ARB analysis KSGR-6a and $-6 \mathrm{~b}$ clustered separately, but both were included in the pMC2A33 cluster, while 6C clustered with the MOB7-9 group. KSGR-8 and KSGR-9 were associated with clades of uncultured Euryarchaeota known as RC-V (Fig. 5b) and LDS cluster (Fig. 5c), respectively [46].

Clones belonging to the LDS clade were represented in all six clone libraries, although with a variable percentage (Table 2). The RC-V cluster was also common, but absent from the KS18 library (Table 2).

Besides these major groups, five other clusters were also most closely related to environmental clades of the Euryarchaeota. Clusters KSGR-3 (clone frequency $8 \%$ ) and KSGR-2 were both closely related to environmental sequences from South African gold mines previously classified as an uncultured group within the Euryarchaeota (SAGMEG-1), [56]. The majority of the sequences in KSGR-3 originated from the KS18 clone library (Table 2). The expected T-RFLP fragment size (318 or $319 \mathrm{bp}$ ) for members of this group relatively closely matches the most abundant TRFLP- OTUs (O17, O18), but did not meet the matching criteria. In KSGR-4, the four clone sequences originating from clone library KS17 and one sequence from KS7 were affiliated with sequences of anaerobic $\mathrm{CH}_{4}$ oxidizing ANME1 group [57]. Only two sequences, one each from clone library KS20 and KS17, were related to the cultivated sequences of typical acetoclastic methanogens, 


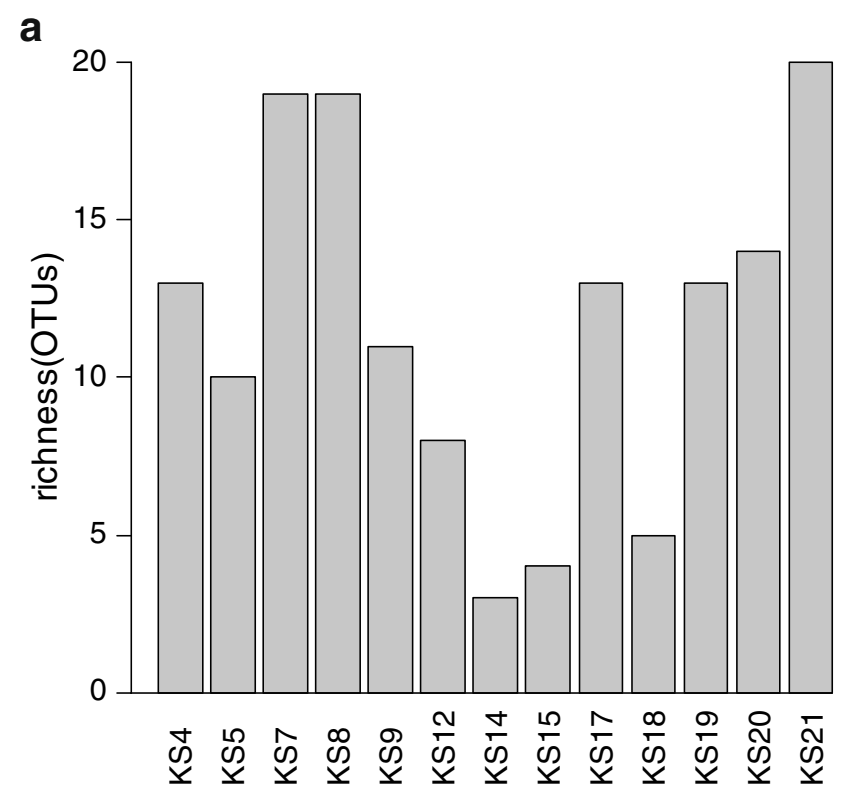

b

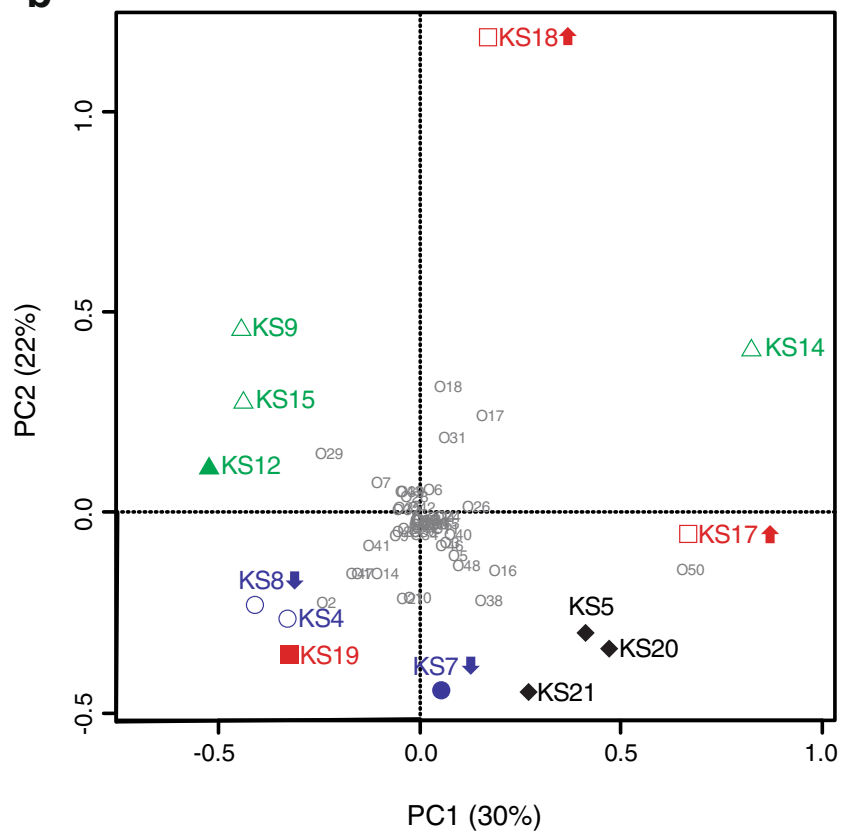

$\begin{array}{ll}\text { Sediment group: } & \text { Groundwater influence: } \\ \Delta \triangle S 1 \diamond \diamond \mathrm{S} 2 & \text { warm } \\ \triangle \mathrm{S3} \square \square \mathrm{S} 4 & \text { cold } \\ \text { (filled symbol = below chemocline) } & \end{array}$

i.e., of the Methosarcinales, and no clones with similarity to other groups of known methanogens were obtained. A number of sequences (KS7_12a, KS8_12, KS18_25, KS20_16a, and KS20_11a) were only distantly related to any published archaeal sequences ( $70-80 \%$ sequence identity with closest match from public databases), but were recognized as archaeal sequences by the RDP classifier. Best BLAST matches (both on the full-length sequence as well as on the $3^{\prime}$ and $5^{\prime}$ ends of the sequences) were other
Figure 3 Diversity of archaeal communities in KS. a Richness of archaeal Operational Taxonomic Units based on T-RFLP peak detection. b Ordination biplot (scaling method 2) of principal component analysis $(P C A)$ of T-RFLP profiles derived from sediment samples obtained from different locations. The first two principal components $(P C)$ are shown. Symbols indicate the sediment group (Table 1), the position of the sediment above or below the main chemocline, and the influence of groundwater at the sampling site, if any. Small labels indicate T-RFLP peaks representing OTUs; $30 \%$ of the total variance in the OTU data was represented on axis PC1, an additional $22 \%$ on axis PC2. Sites close to each other on the ordination plot have similar species composition. The position of OTU's relative to the sites indicates correlation of the relative peak area of the OTU as a proxy for abundance: for example, sample KS 17 is indicated to have had a high abundance of OTU O50 while this phylotype was in low abundance or absent in the Gisenyi transect samples to the left

environmental archaeal 16S rRNA gene sequences. We did not find evidence for these sequences to be chimeric. In the ARB analysis, these sequences, as well as the KSGR-7 sequences, clustered partially with the LDS and partially with the RC-V cluster, indicating that KSGR-7 probably does not represent a separate phylogenetic entity.

The distribution of the Lake Kivu clone library into the major phylogenetic groups and environmental clusters was compared with 11 published archaeal clone libraries from lake sediments (Table 3). The comparison shows that members of the Methanomicrobiales and Methanosaetaceae are common and often dominant constituents of lake sediment archaeal communities that were surprisingly absent or rare in the Lake Kivu library. In fact, KS yielded by far the lowest incidence of known methanogens of any of the analyzed lake sediment archaeal libraries. In turn, several KSGR (KSGR-3, KSGR-1c, and KSGR-6c) are not present in any of the published libraries. In two cases (KSGR-2 and KSGR-4) a single representative was found in the Lake Honghu library only. Other groups, e.g., Crenarchaeota similar to KSGR-1a, and Thermoplasmata similar to KSGR-6a, and $-6 b$, were frequently present in the published libraries. The environmental clusters RC-V and LDS (KSGR-8 and -9) were well represented in four of the published libraries but absent or rare in the others.

In silico T-RFLP revealed a considerable diversity of predicted terminal restriction fragment sizes (T-RFs; Table $\mathrm{S} 1$ in the ESM in the supplementary material). Matching T-RFLP OTUs could only be assigned in a few cases with confidence.

\section{Discussion}

Diversity of Archaea in Lake Kivu sediment

The importance of methanogenic Archaea for production of $\mathrm{CH}_{4}$ in lacustrine sediments is well recognized [58]. Recently, Archaea, including freshwater Archaea have been 


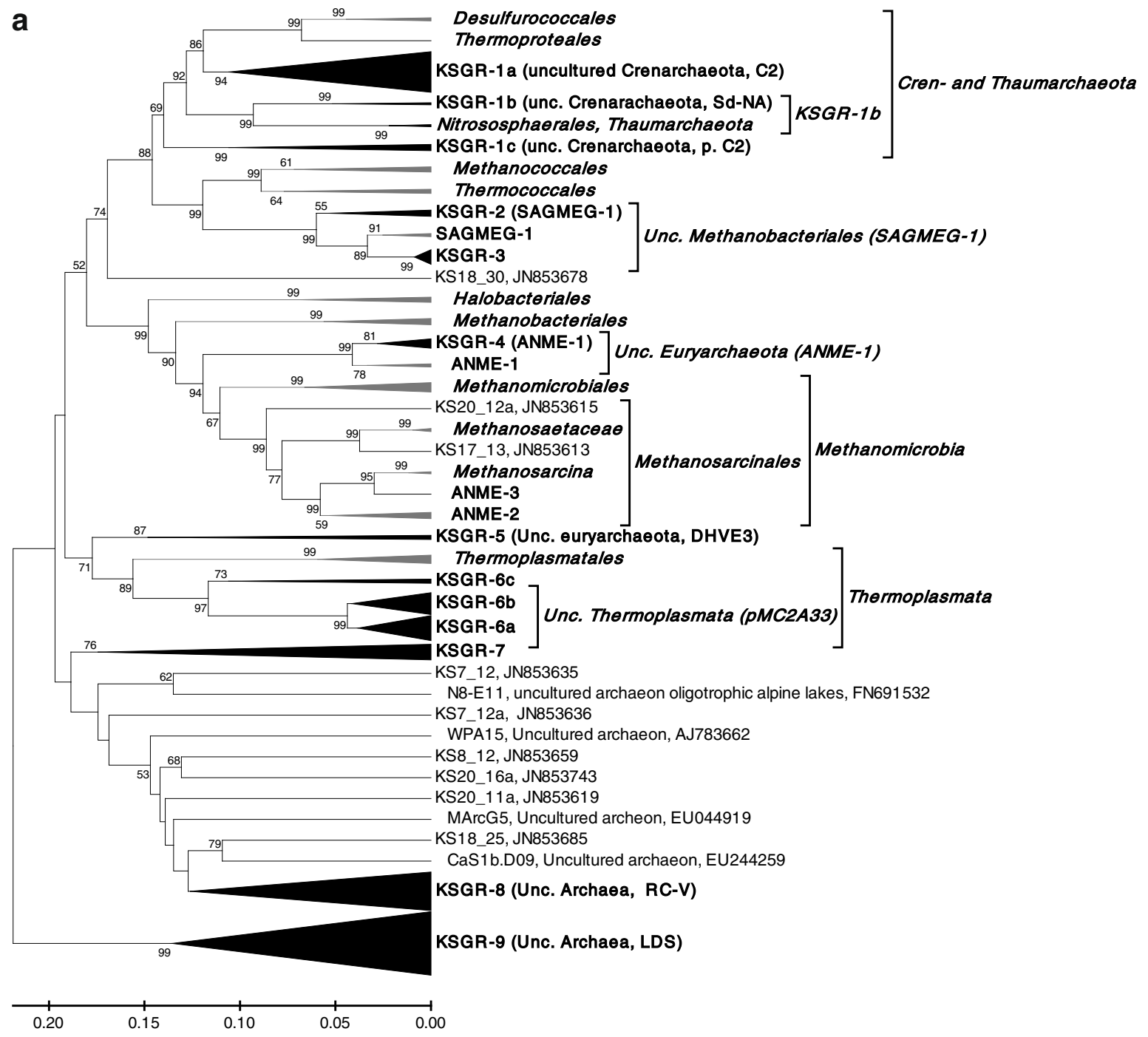

b

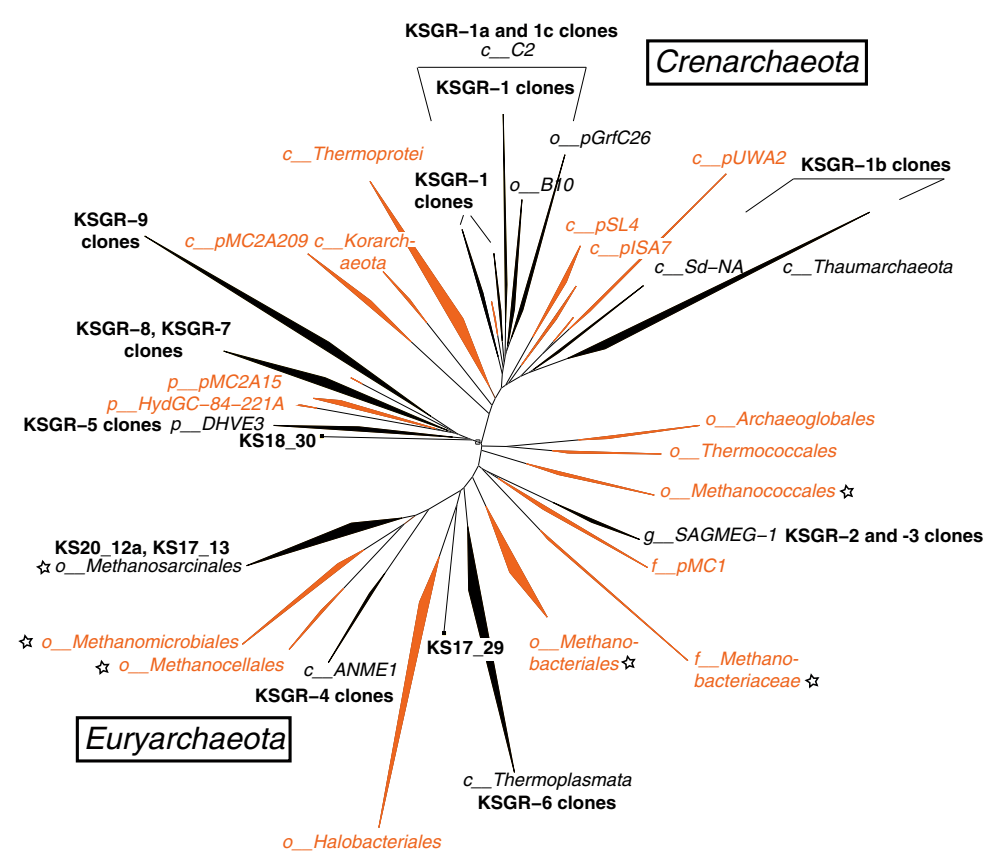


Figure 4 a Phylogenetic relationships of Archaea sequences from sediments and reference sequences. Collapsed branches shown in black contain sequences from Lake Kivu. The phylogeny of the shown consensus tree was inferred using the UPGMA [47] method in MEGA5 [44]. Taxonomic identity of the observed clusters refers to the Greengenes taxonomy and is partially based on the information obtained from the ARB-based analysis (see b). The percentage of replicate trees in which the associated taxa clustered together in the bootstrap test (500 replicates) are shown next to the branches. The evolutionary distances were computed using the Kimura two-parameter method [48] and are in the units of the number of base substitutions per site. Ambiguous positions were removed for each sequence pair. b Phylogenetic tree of the domain Archaea, based on the Greengenes reference database and reference tree for ARB. Lake Kivu aligned using the NAST aligner on the Greengenes website, and aligned sequences were added to the reference tree using ARB's quick parsimony method. Domain Bacteria and some clusters of environmental Archaea were removed from the tree to reduce the complexity. Black branches contain Lake Kivu sequences and are labeled with the Kivu sediment groups (KSGR) they contain, other branches contain only reference sequences. The star symbol indicates clades with known methanogens

shown to be important also for other biogeochemical pathways in mesophilic environments, e.g., ammonium oxidation and $\mathrm{CH}_{4}$ oxidation [26, 51]. However, the ecological and biogeochemical role of many environmental Archaea remains yet to be determined. The ecological patterns of environmental Archaea have been studied recently [46, 59], but the distribution of archaeal communities and their diversity in lake sediments remains poorly understood and the number of studied lakes is limited. In the context of the deep meromictic Lake Kivu, this is the first comprehensive study on the archaeal communities in the anoxic sediment of the lake using a molecular approach.

The two approaches used for phylogenetic analysis gave largely homologous results and showed that the sediments of Lake Kivu host a phylogenetically highly diverse archaeal assemblage. A similarly high number of phylogenetic clades has not been reported previously in published studies on Archaea in lake sediments, although the currently still unpublished Lake Honghu library may contain even greater phylogenetic diversity (Table 3 ). The distribution of phylogenetic groups within our libraries varied (Table 2). In contrast to other studies, the observed diversity is therefore at least in part attributable to the beta-diversity within the system. With the exception of the Lake Honghu library $(n=$ 347), published clone libraries contain relatively low numbers of clones $(n=22-84)$. It is not expected that libraries of this size can exhaustively represent the archaeal diversity in a given system, as the observed coverage frequently shows (Table 3). This was confirmed by the increasing trend of the calculated rarefaction curves (data not shown). This is also true for our combined as well as the libraries of individual samples (Table 2). This suggests that obtaining larger clone

Table 2 Phylogenetic composition of clone libraries from six surface sediment samples with distinct origin

\begin{tabular}{|c|c|c|c|c|c|c|c|}
\hline \multirow[t]{2}{*}{ Phylogenetic group } & \multicolumn{6}{|c|}{ No. of sequences in each clone library } & \multirow[t]{2}{*}{ Total sequences } \\
\hline & KS7 & KS8 & KS9 & KS17 & KS18 & KS20 & \\
\hline KSGR-1 (unc. Cren-/Thaumarchaeota) & & & & & & & 38 \\
\hline KSGR-1a (unc. Crenarchaeota, C2) & 3 & 1 & 0 & 8 & 2 & 17 & 31 \\
\hline KSGR-1b (unc. Cren- and Thaumarchaeota) & 0 & 0 & 3 & 0 & 0 & 0 & 3 \\
\hline KSGR-1c (unc. Crenarchaeota, C2) & 1 & 0 & 0 & 0 & 2 & 1 & 4 \\
\hline KSGR-2 (unc. Euryarchaeota, SAGMEG-1) & 0 & 0 & 0 & 0 & 1 & 2 & 3 \\
\hline KSGR-3 (unc. Euryarchaeota, SAGMEG-1) & 0 & 0 & 0 & 0 & 13 & 1 & 14 \\
\hline KSGR-4 (unc. Euryarchaeota, ANME-I) & 1 & 0 & 0 & 4 & 0 & 0 & 5 \\
\hline KSGR-5 (unc. Euryarchaeota, DHVE3) & 1 & 1 & 0 & 0 & 0 & 0 & 2 \\
\hline KSGR-6 (unc. Thermoplasmata) & & & & & & & 29 \\
\hline KSGR-6a (unc. Thermoplasmata, pMC2A33) & 5 & 2 & 1 & 5 & 0 & 0 & 13 \\
\hline KSGR-6b (unc. Thermoplasmata, pMC2A33) & 5 & 4 & 0 & 3 & 1 & 1 & 14 \\
\hline KSGR-6c (unc. Thermoplasmata, MOB7-9) & 0 & 1 & 0 & 1 & 0 & 0 & 2 \\
\hline KSGR-7 (unc. Euryarchaeota, RCV/LDS) & 3 & 1 & 0 & 2 & 0 & 1 & 7 \\
\hline KSGR-8 (unc. Euryarchaeota, R-CV) & 4 & 8 & 4 & 2 & 0 & 2 & 20 \\
\hline KSGR-9 (unc. Euryarchaeota, LDS) & 6 & 7 & 14 & 3 & 4 & 4 & 38 \\
\hline Methanosarcinales & 0 & 0 & 0 & 1 & 0 & 1 & 2 \\
\hline Others/ambiguous & 2 & 1 & 0 & 0 & 3 & 2 & 8 \\
\hline Total number of sequences & 31 & 26 & 22 & 29 & 26 & 32 & 166 \\
\hline Groups represented (incl. subgroups) & 9 & 8 & 4 & 9 & 6 & 9 & 14 \\
\hline Coverage (OTUs at $10 \%$ distance) & 0.22 & 0.37 & 0.7 & 0.53 & 0.68 & 0.38 & 0.62 \\
\hline
\end{tabular}




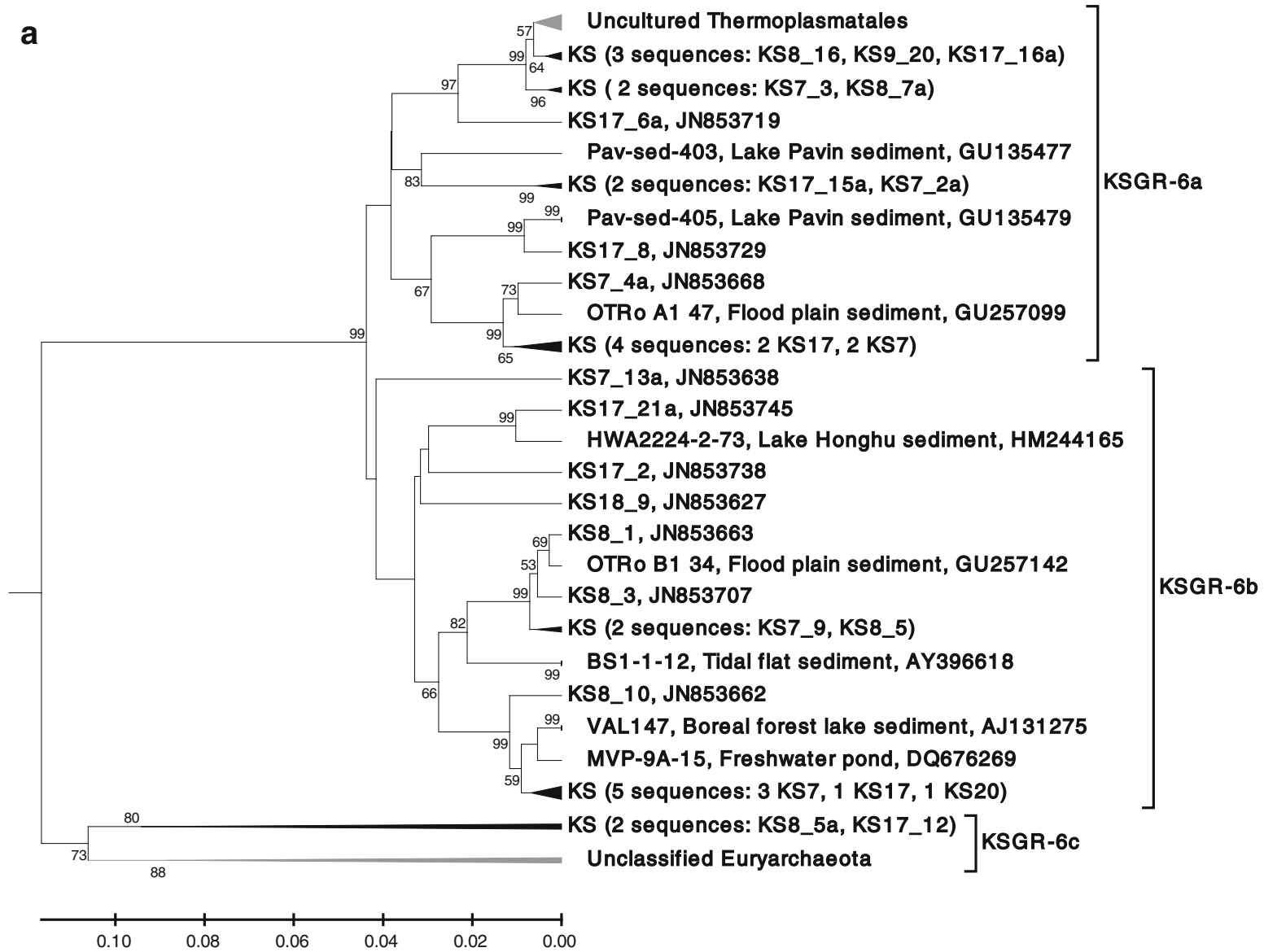

b

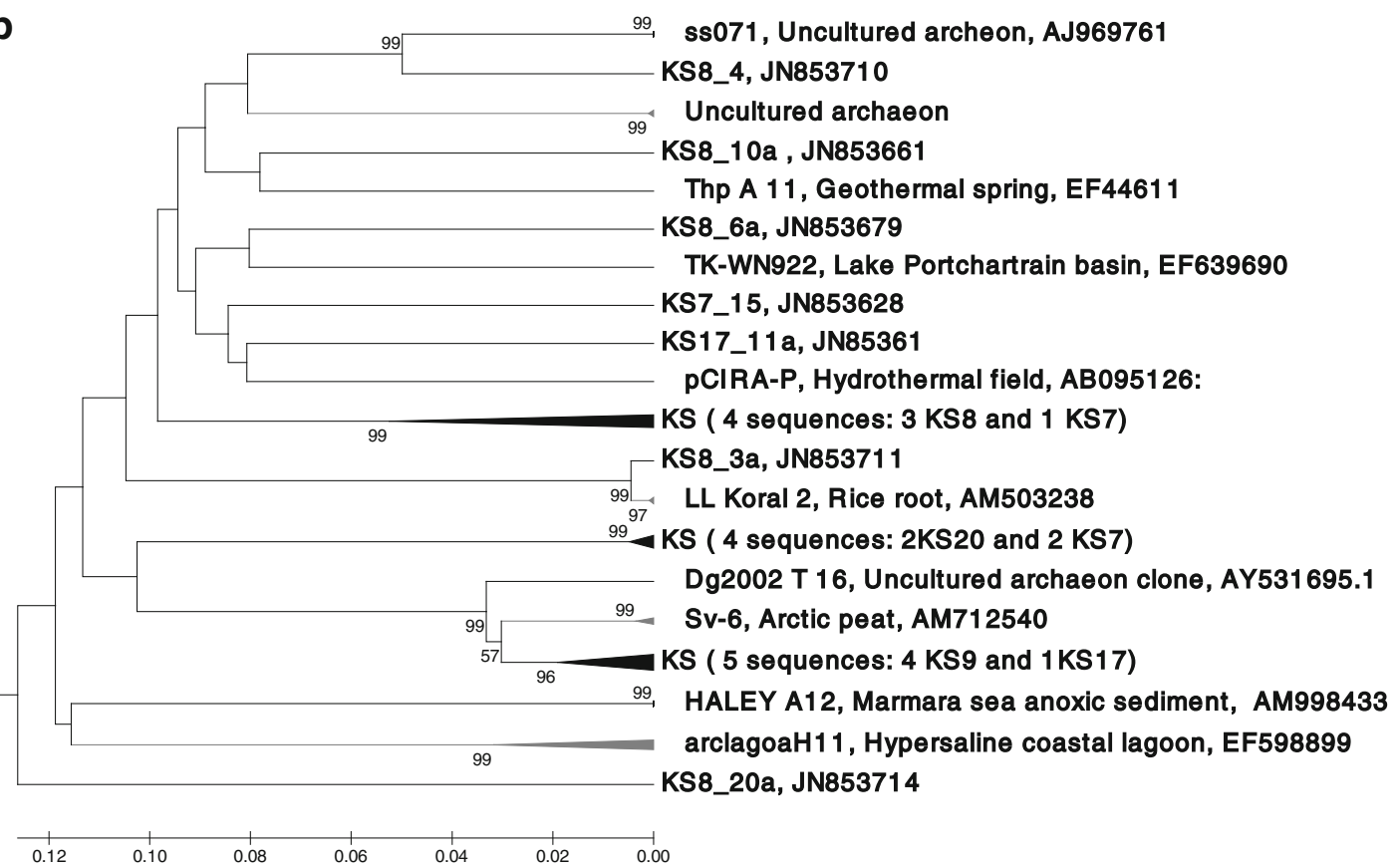

Figure 5 Partial trees showing details within collapsed branches in the phylogenetic tree shown in Fig. 4. a Group KSGR-6 (uncultured Thermoplasmata). b Group KSGR-8 (RC-V). c Group KSGR-9 (LDS). d Group KSGR-1 (Cren- and Thaumarchaeota) 
${ }_{96}^{99}$ (KS ( 8 sequences: KS9)

99

82

53

94

96

94

99

53

57

70

88

67

83

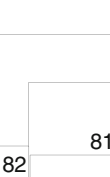

96
99

LDS25, Lake Dagow sediment, AY133913, KS9_16, JN853759

$99 \quad$ CaS1s.03, Stamukhi Lake water, EF014534 KS20_6, JN85372

A190, Saline soil, EU328139

mrR1.52, Coastal arctic ocean, DQ310395

KS8_9a, JN853693

CaR3s.18, Stamukhi lake water, EF014517

CaR3s.35, Stamukhi lake water, EF014515

KS8_9, JN853684

KS ( 2 sequences: KS9_3, KS9_10)

KS7_16, JN853634

ANNA-E9, Uncultured archaeon, FR820719

${ }^{99} \mathrm{KS}$ (2 sequences: KS17_14a, KS17_23a)

NE31CO5CA, Microbial mat, DQ423956

KS8_15, JN853656

LDS27, Lake Dagow sediment, AY133915

LDS30, Lake Dagow sediment, AY133918

KS18_3, JN853680

NATA-F5, Uncultured archaeon, FR820683

KS20_15, JN853754

KS8_11, JN853660

NE47CO9cA, Microbial mats, DQ424773

NE41 F08cA, Microbial mats, DQ424483

KS17_10a, JN853620

Sai E4 20, Flood plain sediment, GU257035

KS20_8, JN853735

KuA21, Ground water, AB077231

SS016, Sediment Salton Sea, EU329753

KS (2 sequences: KS8_15a, KS20_6a)

MOB4-8, Deep subsurface water, DQ841228

NE31D02cA, Microbial mats, DQ423964

KS8_7, JN853689

KS9_13, JN853744

D64AR30R55, Rice field, AM778346

CaS1b.D11, Arctic Shelf, EU244255

KS7_18a, JN853607

mrR2.14, Arctic water, DQ310441

LDS10, Lake Dagow sediment, AY133897

KS (2 sequences: KS8_8, KS8_6)

KS7_4, JN853670

KS (6 sequences: 2 KS7, 3 KS18, 1 KS20)

KS7_11, JN853647

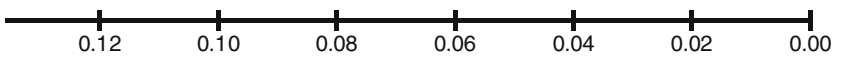

Figure 5 (continued) 


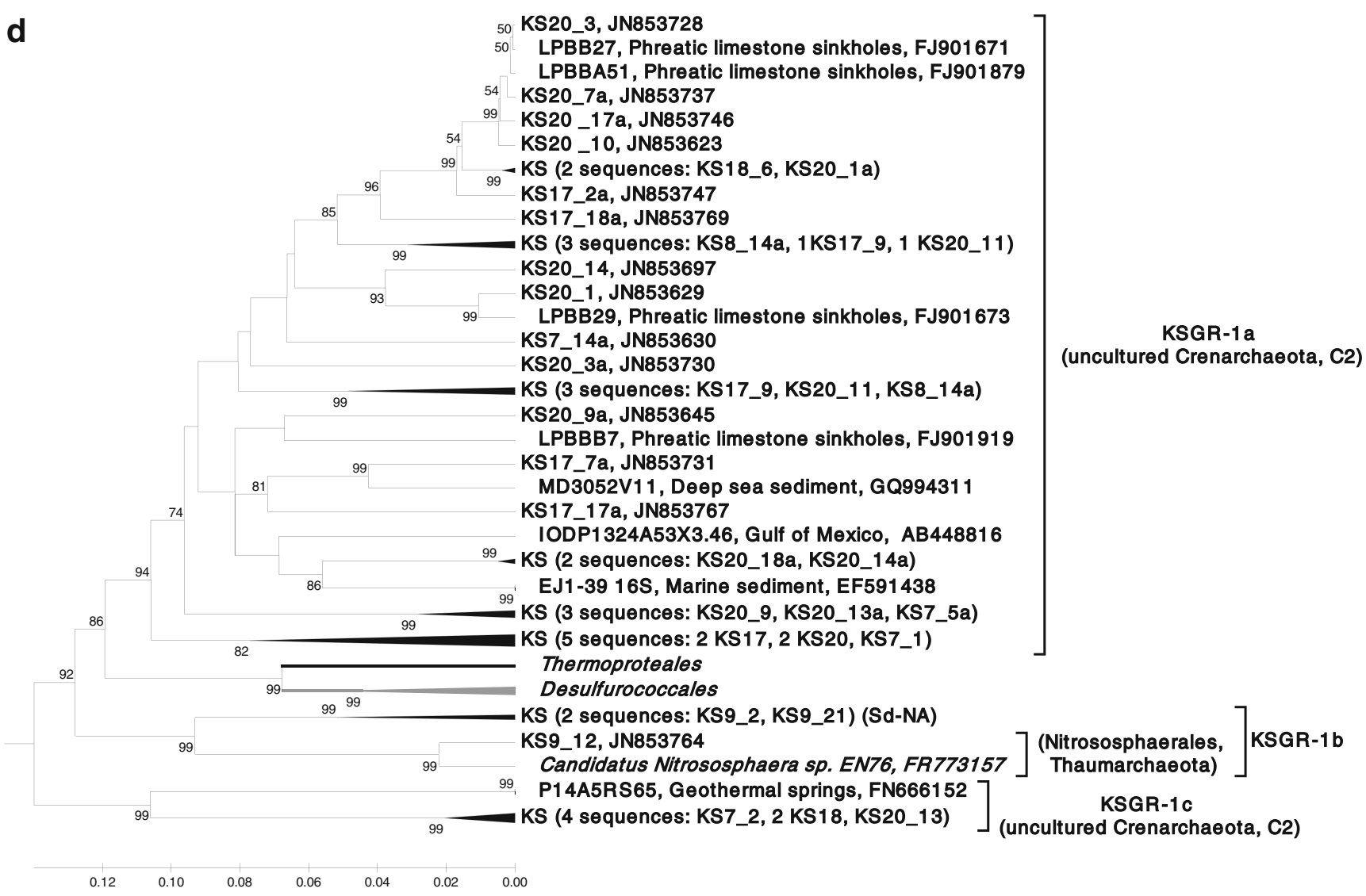

Figure 5 (continued)

libraries or applying next-generation sequencing methods would further increase the diversity observed in Lake Kivu but also in other environments. Even given the limitations of our methodology, we were able to observe several archaeal clades that have not been previously detected in lake sediments, e.g., the SAGMEG-1 sequences in KSGR-2 and KSGR-3, the crenarchaeal/thaumarchaeal sequences of KSGR-1c, and the Thermoplasma group MOB7-9 of KSGR$6 c$. Our study therefore significantly expands the known diversity of lake-sediment Archaea.

\section{Environmental Crenarchaeota}

It is well established that archaeal communities in freshwater habitats contain members of the Crenarchaeota. In Lake $\mathrm{KS}$, we observed considerable diversity within the uncultured crenarchaeota (KSGR-1). The majority of these sequences were related to the environmental $\mathrm{C} 2$ cluster, but other sequences were related to the Sd-NA cluster and one sequence clustered with the genus Candidatus Nitrososphaera. Mesophilic freshwater crenarchaeota were first detected in Lake Michigan sediment [52, 60] and have since been observed in various other lake sediments (see Table 3, group KSGR-1). The phreatic limestone sinkholes that were the origin of many of the best matches to our sequences in this group are freshwater environments characterized by anoxic karstic water with high alkalinity and a tropical temperature regime. [55].

\section{Environmental Euryarchaeota}

Acetoclastic methanogens of the order Methanosarcinales (most frequently Methanosaetaceae) as well as the generally hydrogenotrophic Methanomicrobiales were typically detected as abundant groups in most previous studies on lake-sediment Archaea (Table 3). This is observed in the studies listed in Table 3 and also in Rotsee, Switzerland [61], and Lake Biwa in Japan [62] and is evident from the meta-analysis by Auguet et al. [59]. In Lake Kivu, external electron acceptors such as metal oxides, nitrate, and sulfate are generally expected to be absent in the deep water and thus also in the sediments. Under these conditions fermentation, methanogenesis, and chemolithotrophic acetogenesis are likely to be the main catabolic pathways throughout the sediment. The majority of $\mathrm{CH}_{4}$ from Lake Kivu has been demonstrated to be of biological origin, and biochemical evidence indicates that both acetoclastic and hydrogenotrophic methanogenesis are important in the lake $[11,15]$. While clone libraries are not a quantitative measure of abundance, the lack of methanogens in KS clone libraries was nevertheless unexpected. Coverage 


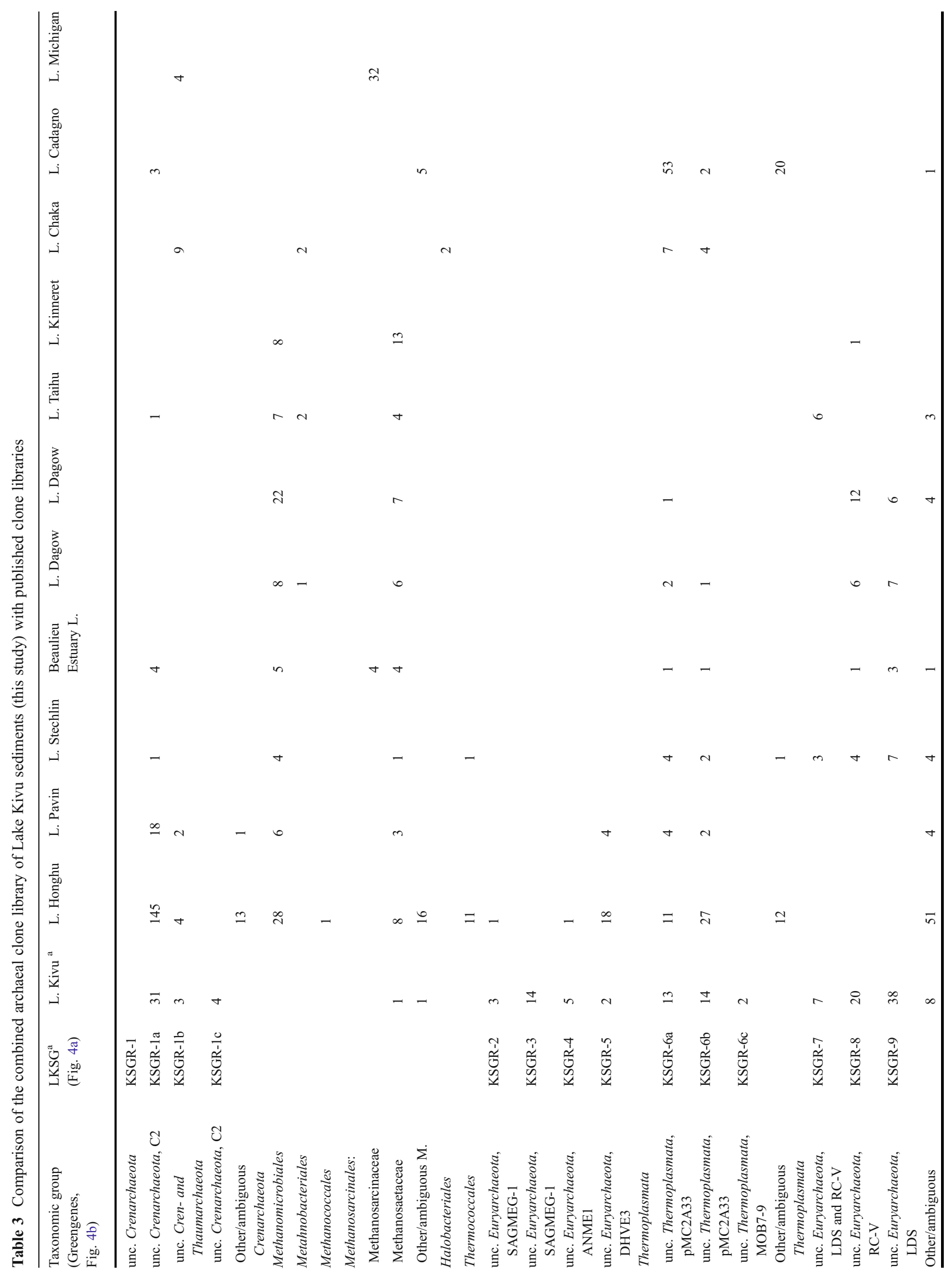


was generally low for our libraries (Table 2). However, this is also true for several previous studies that found known methanogens, such as the Methanomicrobiales, to be abundant in their clone libraries (Table 3). Comparison of clone sequences with T-RFLP (Table S1, supplementary material) indicate that not all T-RFLP OTUs are represented in the library. A bias of the Archaea-specific primer pair used against the documented methanogenic Archaea is unlikely, as amplification of a wide range of methanogens is generally achieved with this primer set [21, 32, 33, 63], and e.g., Methanosarcina was readily amplified as a positive control by the PCR reaction.

It is also unlikely that we accidentally failed to sample the methanogenic zone due to the sampling method: we sampled surface sediment to a maximum depth of $5 \mathrm{~cm}$, outgassing may have mixed sediment even deeper in some cores. Even in lakes with an oxic water column this sampling depth would usually reach into the methanogenic zone. In Lake Kivu, the water column itself provides conditions suitable for methanogenesis, and therefore the entire sediment is probably methanogenic as well. While methanogenesis may take place in the water column, analysis of sediment trap data indicated that carbon mineralization, and thus methane production in the anoxic water column, was negligible in terms of overall fluxes [11], indicating sediment as the main location for methanogenesis.

A previous study on an enrichment of acetoclastic methanogens from KS reported on Methanosarcina-like organisms $[12,27]$. However, this study was based on an enrichment under laboratory conditions and the classification of the organism was apparently primarily based on morphological criteria. Therefore the study provides very little information on the methanogens present in-situ in KS. The apparently low abundance of the typical acetoclastic methanogens (e.g., Methanosaetaceae), and lack of evidence for hydrogenotrophic methanogens raises the question whether some of the diverse environmental clades of Archaea that are abundant in Lake Kivu could be involved in methanogenesis. Possible candidate groups would be KSGR-2, KSGR-3 (SAGMEG1), and KSGR-4 (ANME1), which cluster among the established methanogenic archaeal lineages. The Marine Sediment Bacteria group 1 (MSBL 1, not shown in our figures), which is distantly related to the SAGMEG-1 group (KSGR-2 and KSGR-3), has previously been indicated as methanogenic [59]. Additional research will be required to test this hypothesis.

Euryarchaeotal sequences related to anaerobic $\mathrm{CH}_{4}$ oxidizers (ANME1) were detected primarily in the clone library of the hydrothermal site KS17. Our data indicate that the hydrothermal inflow is fully reduced and can probably not support microbial consortia performing anaerobic $\mathrm{CH}_{4}$ oxidation in this area. Pasche et al. reported mcrA sequences related to the ANME1 cluster to be abundant in the deep 
anoxic water column of Lake Kivu in the absence of electron acceptors [11]. They therefore postulated that these sequences may represent methanogenic relatives of the ANME1 $\mathrm{CH}_{4}$ oxidizers. A recent study by Lloyd et al. also indicated that ANME-like Archaea are probably capable of methanogenesis [64]. Further studies are needed to determine if these microorganisms act as methanogens, anaerobic methane oxidizers, or both. Alternatively an increased sequencing effort may yet demonstrate the presence of known hydrogenotrophic methanogens, in which case their actual abundance should be determined.

The clones affiliated with the environmental LDS clusters were ubiquitous in KS. LDS cluster sequences were originally retrieved from the sediments of Lake Dagow, a temperate lake [65] but the group was also predominant in arctic coastal waters including the Mackenzie River, Mackenzie Lake, a Stamukhi Lake [66, 67] and several other lake sediments (Table 3; Lake Stechlin and Beaulieu Estuary Lake). Among all the observed clusters, the LDS group was distinguished by a particularly diverse phylogenetic composition and long-branch lengths in our phylogenetic analysis. The LDS group is generally assigned to the Euryarchaeota [46], but appears to represent a very distinct cluster within the Archaea.

Another major cluster (RC-V) of environmental sequences was originally retrieved from rice-field soil [32]. But like the LDS group, this clade has been shown to be frequently present with high diversity in freshwater habitats [46]. Both groups have been shown to have remarkable diversity and have been found in a great variety of environmental habitats. Additionally, both groups probably include lineages with specific adaptations to freshwater habitats [46]. Due to lack of cultivated representatives, it is currently difficult to link the LDS and RC-V clusters with their ecological role and we do not know their metabolic capacities. However, their occurrence in anoxic sediments, particle-rich riverine water, and soil probably indicate a linkage to organic carbon decomposition [67].

Diversity and controls of archaeal community structure in Lake Kivu sediment

The high phylogenetic diversity and different population structures of Archaea found in KS may be related to the environmental constraints imposed by the pronounced physico-chemical gradients in the water column. It may also in part reflect the locally different geochemical conditions in areas affected by groundwater inflows entering the lake at different depths. A similar influence was proposed by Zemskaya and coworkers [68] to explain the high diversity of Archaea in sediments from a mud volcano in southern Lake Baikal.
T-RFLP analysis of the archaeal community structure of the surface sediment samples revealed the heterogeneity of the archaeal community structure between sampling locations in greater detail, as depicted in the PCA plot (Fig. 3b). However, a large number of samples were aggregated at the bottom right quadrant of the PCA plot. The similarity in the community composition of samples KS21, KS20, and KS5 might be explained by the uniform characteristics of sediments in group S2, and the increased salinity and gas concentrations in the deep water below the chemocline (Table 1; Fig. 2a). A distinct bacterial community and distinct $m c r A$ phylotypes were observed in the water below the main chemocline by Pasche et al. [11]. Furthermore, sediment cores from the transect offshore of Gisenyi clustered separately in the top left quadrant of the PCA plot. This group of samples (K12, K15, and K9) belong to sediment group S1, which is distinguished from other samples by very low amounts of TIC and TOC (Table 1), probably indicating a local source of detrital siliciclastic material.

The distinct archaeal community structure observed within sediments of group S4 is thought to reflect the strong biogeochemical gradients in the area due to the inflow of warm, saline water supplying inorganic electron donors. KS17 appeared as a geochemically unique location with high alkalinity, sulfide and dissolved iron in the water above the sediment, as well as rich in TOC and TS (Table 1). Similarly, the surface sediment KS18 was distinguished by exceptionally high TS content, possibly indicating precipitation of sulfuriron minerals. In contrast, the KS19 site is outside of the direct influence of the hydrothermal water, and its archaeal composition was consequently more similar to that of other sediments.

The sediment samples KS7 (297 m depth) and KS8 $(157 \mathrm{~m})$ taken from the vicinity of cold groundwater inflows had a high richness in T-RFLP OTUs. The extent of groundwater discharge in this area has yet to be determined. Water from the area is assumed to contain elevated sulfate concentrations and sediment has a larger proportion of TOC and TS compared with other areas not excepted to be influenced by groundwater. A ridge structure is visible in the high resolution bathymetry of this site that may indicate local mineral deposits (unpublished data). At KS8, precipitation of minerals from the inflow may change the local conditions in the sediment. We speculate that the more diverse archaeal communities observed here are an effect of cold groundwater flowing through or above the sediment which would supply electron donors and create gradients within the sediment. In agreement with this hypothesis, phylogenetic analysis of the clone library KS7 showed indications of diverse physiological abilities, e.g., in the presence of potentially $\mathrm{CH}_{4}$ oxidizing ANME1-like Archaea and methanogenic Methanosarcinales.

In-silico restriction fragment analysis of our clone library sequences confirmed a high diversity of T-RF sizes, but 
yielded only few clones that could be confidently matched with T-RFLP OTU's (Table S1 in the ESM). For KS18 the abundant T-RF peaks $\mathrm{O} 18$ and O19 could be manually assigned to clones in group KSGR-3 (SAGMEG-1) with some confidence, however the predicted T-RF sizes were about $5 \mathrm{bp}$ different. This may indicate that the applied correction to apparent T-RF sizes [36] was not sufficient for our data. Taking this into account, the general lack of overlap between the two approaches is further evidence that the clone libraries were not exhaustive of the true diversity. Obtaining a better match between community structure and phylogenetic identity would certainly improve our understanding of the ecology of Archaea in Lake Kivu and could be achieved using new high throughput sequencing approaches.

Lake Kivu, a lake with one of the highest methane production rates on record, was shown to contain archaeal assemblages that differ from the typical archaeal community composition of freshwater lake sediments and were dominated by currently uncultured archaeal clades. The ecology of these organisms deserves further study. The sediments in the northern basin of Lake Kivu appeared as a diverse archaeal habitat structured by the presence of cool/fresh and warm/saline groundwater inflows and lake-wide depth-related gradients. These results imply that local variations in geochemistry should be taken into account to properly understand the relevant microbial processes in this habitat and their influence on the biogeochemistry of Lake Kivu.

Acknowledgments We would like to thank the following people: Irene Brunner (Eawag) for performing elemental analysis of the sediment samples and Francisco Vazquez for help with molecular analyses. Fabrice Muvundja, Augustin Gafasi, and the crew of the Gloria for support during the sampling campaign. Tina Lösekann (MPI Bremen) and Carsten Schubert (Eawag), for providing the full set of archaeal sequences from Lago Cadagno sediment. We are grateful to the EPP program of the UNESCO-IHE Institute for Water Education in Delft and Eawag for providing S. Bhattarai with the opportunity to perform this research and to Alfred Wüest (Eawag) for scientific discussions and for providing funding for an additional research visit of S. Bhattarai to complete the manuscript. The sampling campaign and the salary of K.A. Ross were financed by the Swiss National Science Foundation grant IZ70Z0_123923.

\section{References}

1. Kling GW, Evans WC, Tuttle ML, Tanyileke G (1994) Degassing of Lake Nyos. Nature 368:405-406

2. Sigurdsson H, Devine JD, Tchua FM, Presser FM, Pringle MKW, Evans WC (1987) Origin of the lethal gas burst from Lake Monoun, Cameroun. J Volcanol Geoth Res 31:1-16

3. Schmid M, Halbwachs M, Wehrli B, Wüest A (2005) Weak mixing in Lake Kivu: new insights indicate increasing risk of uncontrolled gas eruption. Geochem Geophys Geosyst 6:Q07009

4. Newman FC (1976) Temperature steps in Lake Kivu: a bottom heated saline lake. J Phys Oceanogr 6:157-163

5. Tietze K (1978) Geophysikalische Untersuchung des Kivusees und seiner ungewöhnlichen Methangaslagerstätte-Schichtung, Dynamik und Gasgehalt des Seewassers. (PhD thesis) Christian-AlbrechtsUniversität, Kiel

6. IPCC (2007) Climate Change 2007: synthesis report. Contribution of Working Groups I, II and III to the Fourth Assessment Report of the Intergovernmental Panel on Climate Change. IPCC, Geneva, Switzerland

7. Bastviken D, Tranvik LJ, Downing JA, Crill PM, Enrich-Prast A (2011) Freshwater methane emissions offset the continental carbon sink. Science 331:50

8. Bastviken D, Cole J, Pace M, Tranvik L (2004) Methane emissions from lakes: dependence of lake characteristics, two regional assessments, and a global estimate. Glob Biogeochem Cycle 18: GB4009

9. Tranvik LJ, Downing JA, Cotner JB, Loiselle SA, Striegle RG, Ballatore TJ, Dillon P, Finlay K, Fortino K, Knoll LB, Kortelainen PL, Kutser T, Larsen S, Laurion I, Leech DM, McCallister SL, McKnight DM, Melack JM, Overholt E, Porter JA, Prairie Y, Renwick WH, Roland F, Sherman BS, Schindler DW, Sobek S, Tremblay A, Vanni MJ, Verschoor AM, von Wachenfeldt E, Weyhenmeyera GA (2009) Lakes and reservoirs as regulators of carbon cycling and climate. Limnol Oceanogr 54:2298-2314

10. Nayar A (2009) A lakeful of trouble. Nature 460:321-323

11. Pasche N, Schmid M, Vazquez F, Schubert CJ, Wüest A, Kessler JD, Pack MA, Reeburgh WS, Bürgmann H (2011) Methane sources and sinks in Lake Kivu. J Geophys Res 116:G03006

12. Schoell M, Tietze K, Schoberth SM (1988) Origin of methane in Lake Kivu (East-Central Africa). Chem Geol 71:257265

13. Tietze K, Geyh M, Müller H, Schröder L, Stahl W, Wehner H (1980) The genesis of the methane in Lake Kivu (Central Africa). Geol Rundsch 69:452-472

14. Muvundja FA, Pasche N, Bugenyi FWB, Isumbisho M, Müller B, Namugize J-N, Rinta P, Schmid M, Stierli R, Wüest A (2009) Balancing nutrient inputs to Lake Kivu. J Great Lakes Res 35: 406-418

15. Pasche N, Alunga G, Mills K, Muvundja F, Ryves D, Schurter M, Wehrli B, Schmid M (2010) Abrupt onset of carbonate deposition in Lake Kivu during the 1960s: response to recent environmental changes. J Paleolimnol 44:931-946

16. Pasche N, Dinkel C, Müller B, Schmid M, Wüest A, Wehrli B (2009) Physical and biogeochemical limits to internal nutrient loading of meromictic Lake Kivu. Limnol Oceanogr 54:1863-1873

17. Degens E, von Herzen R, Wong H-K, Deuser W, Jannasch H (1973) Lake Kivu: structure, chemistry and biology of an East African rift lake. Geol Rundsch 62:245-277

18. Burggraf S, Jannasch HW, Nicolaus B, Stetter KO (1990) Archaeoglobus profundus sp. nov., represents a new species within the sulfate-reducing archaebacteria. Syst Appl Microbiol 13:24-28

19. Tourna M, Stieglmeier M, Spang A, Könneke M, Schintlmeister A, Urich T, Engel M, Schloter M, Wagner M, Richter A, Schleper C (2011) Nitrososphaera viennensis, an ammonia oxidizing archaeon from soil. Proc Natl Acad Sci U S A 108:8420-8425

20. Rudd JWM, Hamilton RD (1978) Methane cycling in a eutrophic shield lake and its effects on whole lake metabolism. Limnol Oceanogr 23:337-348

21. Banning N, Brock F, Fry JC, Parkes RJ, Hornibrook ERC, Weightman AJ (2005) Investigation of the methanogen population structure and activity in a brackish lake sediment. Environ Microbiol 7:947-960

22. Schleper C (2007) Diversity of uncultivated Archaea: perspectives from microbial ecology and metagenomics. Archaea. Blackwell, New York, pp 39-50

23. Casamayor EO, Borrego CM (2009) Archaea in inland waters. In: Likens GE (ed) Encyclopedia of inland waters, vol 3. Elsevier, Oxford, pp 167-181 
24. Galand PE, Casamayor EO, Kirchman DL, Potvin M, Lovejoy C (2009) Unique archaeal assemblages in the Arctic Ocean unveiled by massively parallel tag sequencing. ISME J 3:860-869

25. Karner MB, DeLong EF, Karl DM (2001) Archaeal dominance in the mesopelagic zone of the Pacific Ocean. Nature 409:507-510

26. Lliros M, Gich F, Plasencia A, Auguet J-C, Darchambeau F, Casamayor EO, Descy J-P, Borrego C (2010) Vertical distribution of ammonia-oxidizing crenarchaeota and methanogens in the epipelagic waters of Lake Kivu (Rwanda-Democratic Republic of the Congo). Appl Environ Microbiol 76:6853-6863

27. Bochem HP, Schoberth SM, Sprey B, Wengler P (1982) Thermophilic biomethanation of acetic acid: morphology and ultrastructure of a granular consortium. Can J Microbiol/Rev Can Microbiol 28:500-510

28. Meyers PA, Teranes JL (2001) Sediment organic matter. In: Last WM, Smol JP (eds) Tracking environmental change using lake sediments, vol 3, Physical and geochemical methods. Kluwer Academic, Dordrecht, pp 239-269

29. DEW (2004) Deutsche Einheitsverfahren zur Wasseruntersuchung (DEW). Wiley, New York

30. Hönerlage W, Hahn D, Zeyer J (1995) Detection of mRNA of nprM in Bacillus megaterium ATCC 14581 grown in soil by whole-cell hybridization. Arch Microbiol 163:235-241

31. Schwarz JIK, Eckert W, Conrad R (2007) Community structure of Archaea and Bacteria in a profundal lake sediment Lake Kinneret (Israel). Syst Appl Microbiol 30:239-254

32. Grosskopf R, Stubner S, Liesack W (1998) Novel euryarchaeotal lineages detected on rice roots and in the anoxic bulk soil of flooded rice microcosms. Appl Environ Microbiol 64:4983-4989

33. Lueders T, Friedrich M (2003) Evaluation of PCR amplification bias by terminal restriction fragment length polymorphism analysis of small-subunit rRNA and mcrA genes by using defined template mixtures of methanogenic pure cultures and soil DNA extracts. Appl Environ Microbiol 69:320-326

34. Ramette A (2009) Quantitative molecular community fingerprinting for estimating the abundance of operational taxonomic units in natural microbial communities. Appl Environ Microbiol 75:10

35. Junier P, Junier T, Witzel K-P (2008) TRiFLe, a program for in silico terminal restriction fragment length polymorphism analysis with user-defined sequence sets. Appl Environ Microbiol 74: 6452-6456

36. Kaplan CW, Kitts CL (2003) Variation between observed and true terminal restriction fragment length is dependent on true TRF length and purine content. J Microbiol Methods 54:121-125

37. R Development Core Team (2011) R: a language and environment for statistical computing. R Foundation for Statistical Computing, Vienna, Austria

38. Oksanen J, Blanchet FG, Kindt R, Legendre P, O'Hara RB, Simpson GL, Solymos P, Henry M, Stevens H, Wagner H (2011) vegan: community ecology package. R package version 1.17-6. http:// CRAN.R-project.org/package $=$ vegan

39. Kindt R, Coe R (2005) Tree diversity analysis. A manual and software for common statistical methods for ecological and biodiversity studies. World Agroforestry Centre (ICRAF), Nairobi. ISBN 92-9059-179-X

40. Borcard D, Gillet F, Legendre P (2011) Numerical Ecology with R. Springer, New York. ISBN 978-1-4419-7975-9

41. Legendre P, Gallagher E (2001) Ecologically meaningful transformations for ordination of species data. Oecologia 129:271-280

42. Huber T, Faulkner G, Hugenholtz P (2004) Bellerophon: a program to detect chimeric sequences in multiple sequence alignments. Bioinformatics 20:2317-2319

43. Wang Q, Garrity G, Tiedje J, Cole J (2007) Naive Bayesian classifier for rapid assignment of rRNA sequences into the new bacterial taxonomy. Appl Environ Microbiol 73:5261-5267
44. Tamura K, Peterson D, Peterson N, Stecher G, Nei M, Kumar S (2011) MEGA5: molecular evolutionary genetics analysis using maximum likelihood, evolutionary distance, and maximum parsimony methods. Mol Biol Evol 28:2731-2739

45. Altschul S, Madden T, Schaffer A, Zhang J, Zhang Z, Miller W, Lipman D (1997) Gapped BLAST and PSI-BLAST: a new generation of protein database search programs. Nucleic Acids Res 25:3389-3402

46. Barberán A, Fernández-Guerra A, Auguet J-C, Galand PE, Casamayor EO (2011) Phylogenetic ecology of widespread uncultured clades of the Kingdom Euryarchaeota. Mol Ecol 20:1988-1996

47. Sneath PHA (2005) Numerical taxonomy. In: Brenner DJ, Krieg NR, Staley JT, Garrity GM (eds) Bergey's manual ${ }^{\mathbb{R}}$ of systematic bacteriology. Springer, New York, pp 39-42

48. Kimura M (1980) A simple method for estimating evolutionary rates of base substitutions through comparative studies of nucleotide sequences. J Mol Evol 16:111-120

49. Ludwig W, Strunk O, Westram R, Richter L, Meier H, Yadhukumar BA, Lai T, Steppi S, Jobb G, Förster W, Brettske I, Gerber S, Ginhart AW, Gross O, Grumann S, Hermann S, Jost R, König A, Liss T, Lüßmann R, May M, Nonhoff B, Reichel B, Strehlow R, Stamatakis A, Stuckmann N, Vilbig A, Lenke M, Ludwig T, Bode A, Schleifer KH (2004) ARB: a software environment for sequence data. Nucleic Acids Res 32:1363-1371

50. McDonald D, Price MN, Goodrich J, Nawrocki EP, DeSantis TZ, Probst A, Andersen GL, Knight R, Hugenholtz P (2012) An improved Greengenes taxonomy with explicit ranks for ecological and evolutionary analyses of bacteria and Archaea. ISME J 6:610 618

51. Schubert CJ, Vazquez F, Lösekann-Behrens T, Knittel K, Tonolla M, Boetius A (2011) Evidence for anaerobic oxidation of methane in sediments of a freshwater system (Lago di Cadagno). FEMS Microbiol Ecol 76:26-38

52. MacGregor BJ, Moser DP, Alm EW, Nealson KH, Stahl DA (1997) Crenarchaeota in Lake Michigan sediment. Appl Environ Microbiol 63:1178-1181

53. Schloss PD, Westcott SL, Ryabin T, Hall JR, Hartmann M, Hollister EB, Lesniewski RA, Oakley BB, Parks DH, Robinson CJ, Sahl JW, Stres B, Thallinger GG, Van Horn DJ, Weber CF (2009) Introducing MOTHUR: open-source, platform-independent, community-supported software for describing and comparing microbial communities. Appl Environ Microbiol 75:7537-7541

54. Sayeh R, Birrien J, Alain K, Barbier G, Hamdi M, Prieur D (2010) Microbial diversity in Tunisian geothermal springs as detected by molecular and culture-based approaches. Extremophiles 14:501-514

55. Sahl JW, Gary MO, Harris JK, Spear JR (2010) A comparative molecular analysis of water-filled limestone sinkholes in northeastern Mexico. Environ Microbiol 13:226-240

56. Takai K, Moser DP, DeFlaun M, Onstott TC, Fredrickson JK (2001) Archaeal diversity in waters from deep South African gold mines. Appl Environ Microbiol 67:5750-5760

57. Lösekann T, Knittel K, Nadalig T, Fuchs B, Niemann H, Boetius A, Amann R (2007) Diversity and abundance of aerobic and anaerobic methane oxidizers at the Haakon Mosby mud volcano, Barents Sea. Appl Environ Microbiol 73:3348-3362

58. Conrad R (2005) Quantification of methanogenic pathways using stable carbon isotopic signatures: a review and a proposal. Org Geochem 36:739-752

59. Auguet J-C, Barberan A, Casamayor EO (2010) Global ecological patterns in uncultured Archaea. ISME J 4:182-190

60. Schleper C, Holben W, Klenk H (1997) Recovery of crenarchaeotal ribosomal DNA sequences from freshwater-lake sediments. Appl Environ Microbiol 63:321-323

61. Falz KZ, Holliger C, Großkopf R, Liesack W, Nozhevnikova AN, Müller B, Wehrli B, Hahn D (1999) Vertical distribution of 
methanogens in the anoxic sediment of Rotsee (Switzerland). Appl Environ Microbiol 65(6):2402-2408

62. Koizumi Y, Takii S, Nishino M, Nakajima T (2003) Vertical distributions of sulfate-reducing bacteria and methane-producing Archaea quantified by oligonucleotide probe hybridization in the profundal sediment of a mesotrophic lake. FEMS Microbiol Ecol 44:101-108

63. Luna G, Stumm K, Pusceddu A, Danovaro R (2009) Archaeal diversity in deep-sea sediments estimated by means of different terminal-restriction fragment length polymorphisms (T-RFLP) protocols. Curr Microbiol 59:356-361

64. Lloyd KG, Alperin MJ, Teske A (2011) Environmental evidence for net methane production and oxidation in putative ANaerobic MEthanotrophic (ANME) Archaea. Environ Microbiol 13:2548-2564

65. Glissman K, Chin KJ, Casper P, Conrad R (2004) Methanogenic pathway and archaeal community structure in the sediment of eutrophic Lake Dagow: effect of temperature. Microb Ecol 48: 389-399

66. Galand P, Lovejoy C, Jrm P, Garneau M, Vincent W (2008) Microbial community diversity and heterotrophic production in a coastal Arctic ecosystem: a stamukhi lake and its source waters. Limnol Oceanogr 53:813-823

67. Galand PE, Lovejoy C, Vincent WF (2006) Remarkably diverse and contrasting archaeal communities in a large arctic river and the coastal Arctic Ocean. Aquat Microb Ecol 44:115-126
68. Zemskaya T, Pogodaeva T, Shubenkova O, Chernitsina S, Dagurova O, Buryukhaev S, Namsaraev B, Khlystov O, Egorov A, Krylov A, Kalmychkov G (2010) Geochemical and microbiological characteristics of sediments near the Malenky mud volcano (Lake Baikal, Russia), with evidence of Archaea intermediate between the marine anaerobic methanotrophs ANME-2 and ANME-3. Geo-Mar Lett $30: 411-425$

69. Lahmeyer O (1998) Bathymetric survey of Lake Kivu. Final report. Republic of Rwanda, Ministry of Public Work, Directory of Energy and Hydrocarbons, Kigali

70. Conrad R, Chan O-C, Claus P, Casper P (2007) Characterization of methanogenic Archaea and stable isotope fractionation during methane production in the profundal sediment of an oligotrophic lake (Lake Stechlin, Germany). Limnol Oceanogr 52:1393-1406

71. Chan OC, Claus P, Casper P, Ulrich A, Lueders T, Conrad R (2005) Vertical distribution of structure and function of the methanogenic archaeal community in Lake Dagow sediment. Environ Microbiol 7:1139-1149

72. Ye W, Liu X, Lin S, Tan J, Pan J, Li D, Yang H (2009) The vertical distribution of bacterial and archaeal communities in the water and sediment of Lake Taihu. FEMS Microbiol Ecol 70:263-276

73. Jiang H, Dong H, Zhang G, Yu B, Chapman LR, Fields MW (2006) Microbial diversity in water and sediment of Lake Chaka, an Athalassohaline Lake in Northwestern China. Appl Environ Microbiol 72:3832-3845 